\title{
Genes in a Refined Smith-Magenis Syndrome Critical Deletion Interval on Chromosome 17p11.2 and the Syntenic Region of the Mouse
}

\author{
Weimin $\mathrm{Bi}^{1,6}$ Jiong Yan, ${ }^{1,6}$ Paweł Stankiewicz, ${ }^{1}$ Sung-Sup Park, ${ }^{1,7}$ Katherina Walz, ${ }^{1}$ \\ Cornelius F. Boerkoel, ${ }^{1}$ Lorraine Potocki, ${ }^{1,3}$ Lisa G. Shaffer, ${ }^{1}$ Koen Devriendt, ${ }^{4}$ \\ Małgorzata J.M. Nowaczyk, ${ }^{5}$ Ken Inoue, ${ }^{1}$ and James R. Lupski ${ }^{1,2,3,8}$ \\ Departments of ${ }^{1}$ Molecular \& Human Genetics, ${ }^{2}$ Pediatrics, Baylor College of Medicine, ${ }^{3}$ Texas Children's Hospital, Houston, \\ Texas 77030, USA; ${ }^{4}$ Centre for Human Genetics, University Hospital Gasthuisberg, Catholic University of Leuven, B-3000 \\ Leuven, Belgium; ${ }^{5}$ Department of Pathology and Molecular Medicine, McMaster University, \\ Hamilton, Ontario L8S 4J9, Canada
}

\begin{abstract}
Smith-Magenis syndrome (SMS) is a multiple congenital anomaly/mental retardation syndrome associated with behavioral abnormalities and sleep disturbance. Most patients have the same $\sim 4 \mathrm{Mb}$ interstitial genomic deletion within chromosome 17p11.2. To investigate the molecular bases of the SMS phenotype, we constructed BAC/PAC contigs covering the SMS common deletion interval and its syntenic region on mouse chromosome 11 . Comparative genome analysis reveals the absence of all three $~ 200-k b$ SMS-REP low-copy repeats in the mouse and indicates that the evolution of SMS-REPs was accompanied by transposition of adjacent genes. Physical and genetic map comparisons in humans reveal reduced recombination in both sexes. Moreover, by examining the deleted regions in SMS patients with unusual-sized deletions, we refined the minimal Smith-Magenis critical region (SMCR) to an $\sim 1.1-\mathrm{Mb}$ genomic interval that is syntenic to an $\sim 1.0-\mathrm{Mb}$ region in the mouse. Genes within the SMCR and its mouse syntenic region were identified by homology searches and by gene prediction programs, and their gene structures and expression profiles were characterized. In addition to 12 genes previously mapped, we identified 8 new genes and 10 predicted genes in the SMCR. In the mouse syntenic region of the human SMCR, 16 genes and 6 predicted genes were identified. The SMCR is highly conserved between humans and mice, including 19 genes with the same gene order and orientation. Our findings will facilitate both the identification of gene(s) responsible for the SMS phenotype and the engineering of an SMS mouse model.
\end{abstract}

\begin{abstract}
Smith-Magenis syndrome (SMS) is a contiguous gene-deletion syndrome (Greenberg et al. 1991), in which a distinct and consistent phenotype is associated with deletion of a portion of chromosome band 17p11.2 (Smith et al. 1986; Stratton et al. 1986). The clinical features of SMS patients include mental retardation, delayed speech and motor development, behavior problems, sleep disturbance, minor craniofacial abnormalities, short stature, and brachydactyly (Greenberg et al. 1991). Less common features include otolaryngological abnormalities, hearing impairment, opthalmological abnormalities, and renal and cardiac abnormalities (Chen et al. 1996; Greenberg et al. 1996). The incidence of SMS is $\sim 1$ : 25,000 births, which is likely underestimated given the often subtle clinical features, particularly early in life (Greenberg et
\end{abstract}

\footnotetext{
${ }^{6}$ These authors contributed equally to this work.

7Present address: Department of Clinical Pathology, Seoul National University Hospital, Seoul 110-744, South Korea. ${ }^{8}$ Corresponding author.

E-MAIL jlupski@bcm.tmc.edu; FAX (713) 798-5073.

Article and publication are at http://www.genome.org/cgi/doi/10.1101/ gr.73702.
}

al. 1991). A heterozygous interstitial deletion of $\sim 4 \mathrm{Mb}$ in chromosome $17 \mathrm{p} 11.2$ was identified in $>90 \%$ of SMS patients, whereas the remaining patients have rare smaller- or largersized deletions (Greenberg et al. 1991; Juyal et al. 1996; Chen et al. 1997).

To narrow the critical interval responsible for the SMS phenotype, STS content mapping was performed on somatic cell hybrids refining the deleted chromosome from 62 SMS patients. A common deletion region was defined between markers D17S58 and cDI17-498 (Juyal et al. 1996). Ten patients with a deletion distinct from the common deletion region were identified, and molecular analyses of these patients delineated an SMS critical interval between D17S29 and cCI17-638 (Elsea et al. 1997). Three copies of a low-copy repeat (SMS-REPs) were identified within the common deletion region, and homologous recombination and unequal crossing over between the flanking SMS-REPs were shown to comprise the mechanism responsible for the genomic deletion (Chen et al. 1997). The predicted reciprocal duplication of the SMS common deletion region dup(17)(p11.2p11.2), which was identified recently, causes a subtle clinical syndrome (Potocki et al. 2000). 
The first gene identified within the SMS common deletion region, snU3, encodes a small nuclear RNA U3 (Chevillard et al. 1993). Since then, more than 15 genes have been mapped. In addition, a large number of ESTs with no homology to known genes were identified (Seranski et al. 1999). However, a potential role for any of these genes in the SMS phenotype through haploinsufficiency effects remains unclear.

The shaker-2 (sh2) mouse represents a mouse model for human deafness (DFNB3), resulting from mutation of MYO15A (Wang et al. 1998; Liburd et al. 2001). A physical map of the $s h 2$ region revealed that 11 genes mapping within the SMS common deletion region have murine homologs in the sh2 region (Probst et al. 1998). The gene order was not completely conserved secondary to two independent genomic inversions. However, the order of the seven genes within the critical region was apparently conserved between humans and mice.

To identify potential causative gene(s) of the SMS phenotype and to facilitate the construction of an SMS mouse model, we constructed a large insert clone contig of the SMS common deletion region and its syntenic region in the mouse. Here we report the comparative genomic analysis between humans and mice, comparison of the human genetic and physical maps, delineation of the SMS critical region (SMCR), and the identification and characterization of genes in both human SMCR and the mouse syntenic region.

\section{RESULTS}

\section{Construction of the BAC/PAC Contig of the SMS Common Deletion and Its Syntenic Region in the Mouse}

We constructed a BAC/PAC contig covering the SMS common deletion region with a minimal tilting path of 30 clones (Fig. 1). Three low-copy repeat gene clusters were identified previously inside and flanking the SMS deletion region (Chen et al. 1997). Clones specific to an individual SMS-REP were identified based on cis-morphisms, sequence differences among repeats on the same chromosome (Park et al. 2002). From the DNA sequence of these clones, we deduced that the size of the common deletion region including the three SMS-REPs is $\sim 3.7$ $\mathrm{Mb}$ and the sizes of the SMS-REPs are between 176 and $256 \mathrm{~kb}$. The middle SMS-REP is inverted with respect to the direct orientation of the proximal and distal copies (Park et al. 2002).

We also constructed a complete BAC contig covering the syntenic mouse region (Fig. 2). The DNA sequence from these BACs indicated that the SMS-REPs are not present, consistent with previous hybridization-based observations (Chen et al. 1997; Probst et al. 1999). The 28 genes that mapped within or around the common deletion region of SMS have homologs on the syntenic region in mouse chromosome 11. Compari-

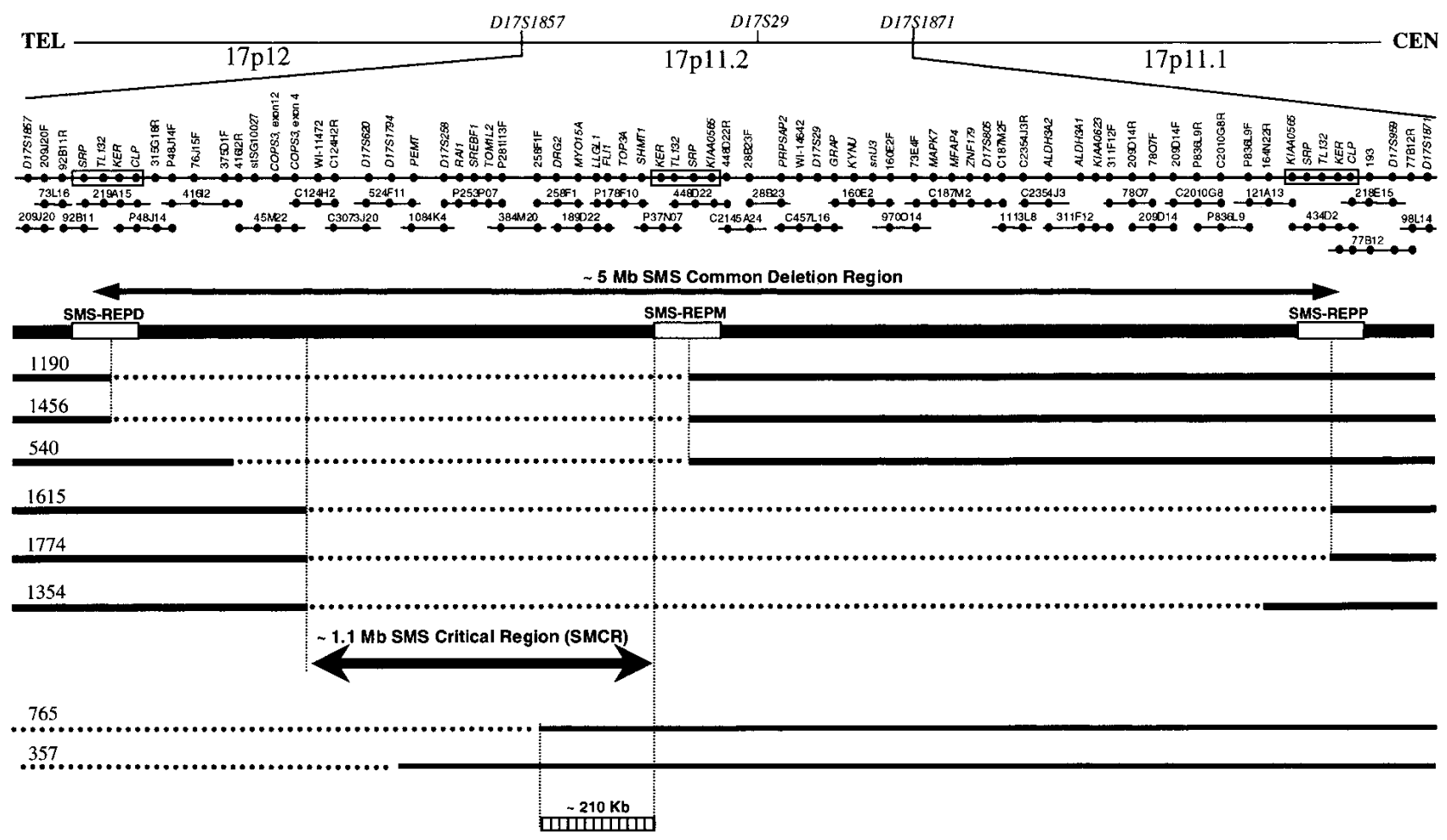

Figure 1 The Smith-Magenis critical region (SMCR) refined by breakpoint studies of patients with deletions in 17p11.2. The SMS common deletion region falls between $D 175959$ and D17S1857, including SMS-REPs. Above are shown genetic markers and the cytogenetic bands on 17p. TEL represents telomeric orientation, and CEN represents centromeric orientation. The minimum BAC/PAC tiling path of the SMS common deletion region is shown toward the top of the figure, with STS-content markers represented by dots and BAC/PAC clones represented by horizontal bars. Clones without a prefix are BACs from RPCI-11; those with prefix P are PAC clones; those with prefix C are CTD clones. BAC end sequences were used as markers with R representing the BAC end sequence derived from the Sp6 primer, and $\mathrm{F}$ representing the sequence from the T7 primer. Above the BAC contig are listed the individual genes and genetic markers from this region. Below, patients are identified by number. The deleted region is indicated by dashed lines, whereas bold lines refer to genomic sequences retained. The distal breakpoints of patients 357 and 765 are outside the SMS common deleted region. The refined $\sim 1.1-\mathrm{Mb}$ SMCR (double-edged bold arrow) and the $\sim 210 \mathrm{~kb}$ (hatched box) inside the SMCR, but not deleted in patient 765 , are indicated.

\section{Genome Research} www.genome.org 


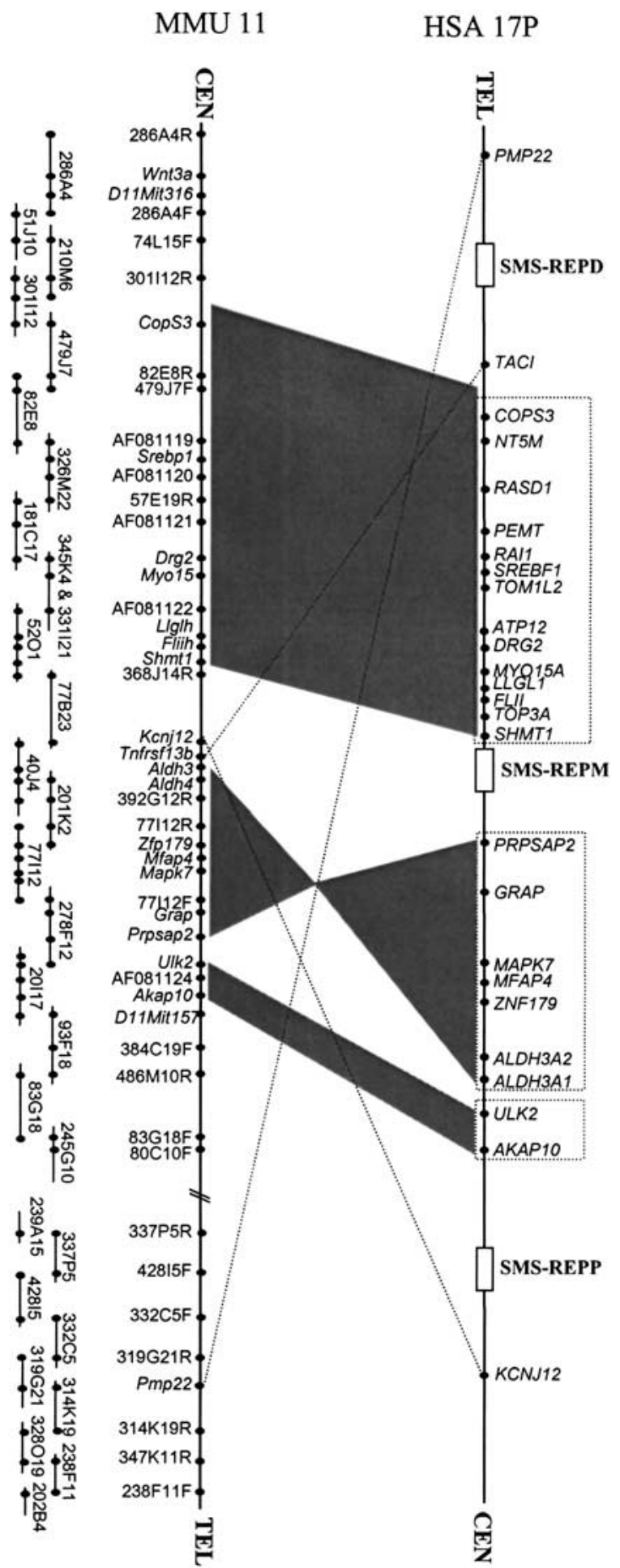

Figure 2 Comparison of the gene order in the human SMS common deletion region and its mouse syntenic region. Genes within the human SMS region on 17p11.2 are shown above. Open boxes represent the SMS-REPs. Below is shown the minimum BAC tiling path of the mouse syntenic region of the SMS common deletion interval and its flanking region. Each BAC clone is represented by a horizontal bar with STS-content markers represented by dots. Blocks of genes that show linkage conservation (i.e., identical gene order) in humans and mice are boxed and connected via gray shading. sons between humans and mice (Fig. 2) confirmed previous observations that gene order is conserved within the genomic interval flanked by the distal and middle SMS-REPs (Probst et al. 1999). In addition, we found that the order of genes ULK2 and $A K A P 10$ is also conserved. The gene order between COPS3 and $A K A P 10$ is conserved with the exception of an inversion between PRPSAP2 and ALDH3A1. In contrast, the gene TACI is located centromeric to distal SMS-REP, whereas KCNJ12 is centromeric to proximal SMS-REP. In the mouse, these genes are adjacent and located in the middle of the syntenic SMS region. $P M P 22$, the gene responsible for Charcot-Marie-Tooth disease type 1A (CMT1A) and hereditary neuropathy with liability to pressure palsies (HNPP; Lupski 1999), mapped telomeric to distal SMS-REP, but it is located in an inverted position with respect to the syntenic SMS region in mice. Thus, during evolution disruptions of linkage conservation apparently occurred in the genomic region around the SMS-REP low-copy repeats.

\section{Comparison between the Physical and Genetic Maps}

We previously identified a striking difference in recombination rates between the sexes in the CMT1A genomic region (Inoue et al. 2001), with reduced recombination noted for the male meiotic map. De novo CMT1A duplication occurs 10 times more frequently in male gametogenesis than in female germ cells (Palau et al. 1993). We hypothesized that reduced recombination may increase unequal crossing over resulting in an increased propensity to generate unequal reciprocal recombination products (Inoue et al. 2001).

We extended the genetic/physical map correlation over an $\sim 8.0-\mathrm{Mb}$ region including both the CMT1A and SMS regions (Fig. 3). Reduced recombination is observed in both genders for most of the SMS region. Interestingly, no parentof-origin frequency differences are observed for de novo SMS deletion (Greenberg et al. 1991; Juyal et al. 1996).

\section{Refining the Smith-Magenis Syndrome Critical Region (SMCR)}

Somatic cell hybrid analysis revealed that the breakpoints in most patients with SMS were located within the distal and proximal SMS-REPs (Chen et al. 1997; data not shown). We used an SMS junction fragment identified by PFGE analysis to distinguish SMS patients with the common deletion from those with an unusual-sized deletion. The breakpoints for these latter SMS patients were analyzed by FISH of patient lymphoblasts using BAC/PAC DNA probes; the results are summarized in Figure 1.

Smaller-sized deletions within $17 \mathrm{p} 11.2$ were identified in six patients who have typical behavioral and physical features consistent with SMS (Table 1). The deleted region for two SMS patients, 1190 and 1456, was mapped between the distal and middle SMS-REPs (Fig. 1). Furthermore, the distal deletion breakpoints for SMS patients 1615, 1774, and 1354 were mapped proximal to COPS3, a gene located within the genomic interval between the distal and middle SMS-REPs (Fig. 1). We therefore conclude that the genomic interval between COPS3 and the middle SMS-REP is the critical region for the major SMS features of mental retardation, craniofacial and behavioral abnormalities, and sleep disturbance. We propose that the dosage-sensitive genes responsible for the SMS phenotype are located inside this newly defined SMCR.

Molecular analyses of three patients, 540, 357, and 765, have been reported (Juyal et al. 1996; Elsea et al. 1997). By our 


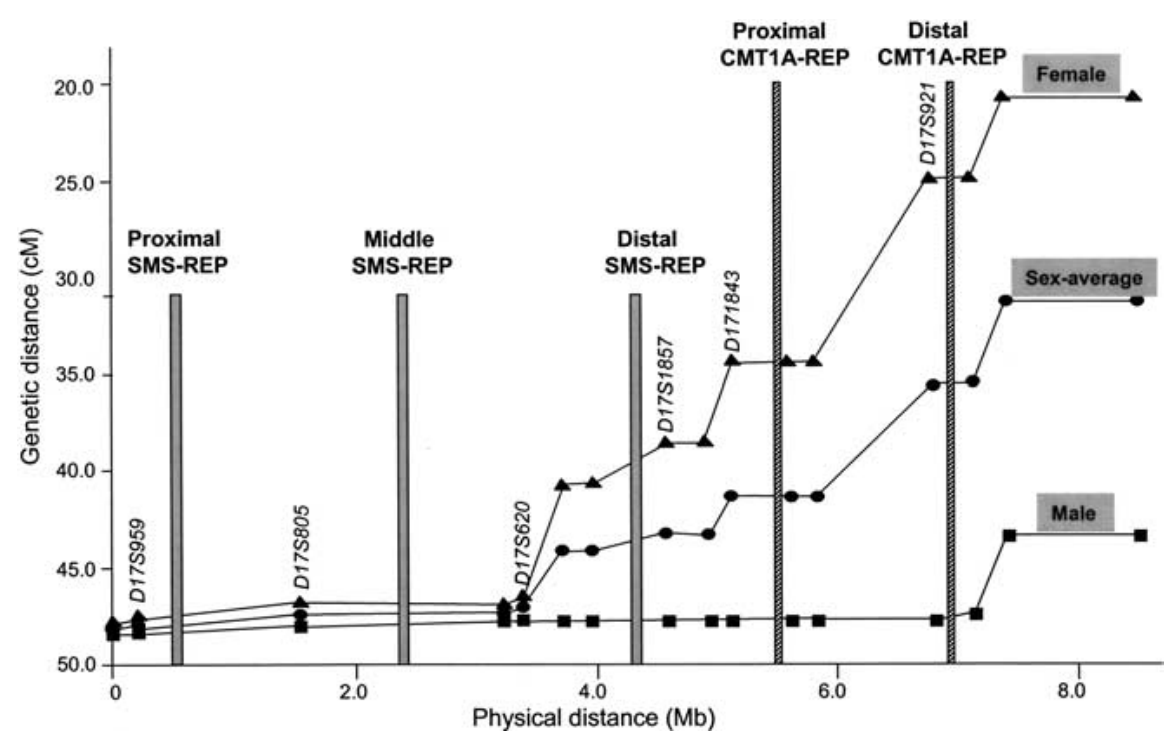

Figure 3 Comparison between genetic and physical maps. The STR genetic markers from Marshfield are aligned to the sequence-based physical map. The marker order is as following: D1751871, $D 175959, D 175805, D 1751794, D 175620, D 175740, D 1752196, D 1751857, D 175953, D 1751843$, $D 17 S 793, D 175918, D 175921, D 1751856, D 175947$, and D17S1803 (markers within the SMS region are underlined). The three SMS-REPs are indicated by gray bars, the two CMT1A-REPs by hatched bars. Reduced recombination in both sexes was observed for most of the SMS region.

mouse genome sequence is $\sim 1.0 \mathrm{Mb}$ with interspersed repeats accounting for only $27.6 \%$. This $\sim 15 \%$ decrease in repetitive sequences in the mouse genome as compared to the human has also been observed in other genomic regions (Amid et al. 2001).

\section{Transcript Map of Human SMCR and Its Syntenic Region in the Mouse}

Potential genes inside the SMCR and the mouse syntenic region were identified through a combination of sequence similarity searches and sequence analysis using gene prediction programs. The potential genes were categorized into three groups: (I) genes, (II) predicted genes, and (III) pseudogenes, using definitions that we employed previously (Inoue et al. 2001).

Within the $\sim 1.1-\mathrm{Mb}$ SMCR, 30 genes were identified, including 20 genes (Group I), 10 predicted genes (Group II), and 3 pseudogenes (Group III; Fig. 4; Table 2). Thus,

clinical analysis, patients 765 and 357 do not have SMS because they do not show self-destructive behavior, sleep disorder, or characteristic SMS facies (Table 1). Mapping of the deletion breakpoints in these patients by PCR analysis of hybrid DNA revealed that the deleted region for patient 765 is located distal to DRG2. Thus, the genomic region responsible for the SMS phenotype may be only $\sim 210 \mathrm{~kb}$ in size (Fig. 1). However, this conclusion is based on the absence of an SMS phenotype in one patient (765) only.

\section{Sequences of the SMCR and Its Syntenic Region in the Mouse}

Ten BAC/PAC clones cover the entire SMCR (Fig. 4). The location of individual clones was confirmed by FISH on lymphoblast chromosomes derived from SMS patients with common deletions. The genomic sequence assembly using public (NCBI, http://www.ncbi.nlm.nih.gov) and private (Celera, http://www.celera.com) genome databases revealed that the size of entire SMCR from the putative distal end of the middle SMS-REP to the promoter of COPS3 is $\sim 1.1 \mathrm{Mb}$.

RepeatMasker identified interspersed repeats that account for $42.19 \%$ of the SMCR. The repetitive elements include $20.54 \%$ Alu sequences and 6.19\% LINE1 sequences, similar to that of chromosome 22 , but different from chromosome 21, which contains $9.48 \%$ Alu and $15.51 \%$ LINE1 sequences, and the CMT1A/HNPP region in $17 \mathrm{p} 12$, that contains 9.97\% Alu and 13.43\% LINE1 elements (Dunham et al. 1999; Hattori et al. 2000; Inoue et al. 2001).

Seven BAC clones cover the mouse region syntenic to SMCR (Fig. 4; NCBI). Genome sequences from the private mouse database (Celera) were initially used to assemble some unordered pieces in the public database. However, subsequent analysis of the public sequence database revealed more robust sequence (fewer small gaps) than the Celera database. The the gene density ( 1 gene per $37 \mathrm{~kb}$ ) is much higher than the average calculated for the complete human genome (1 gene per $90 \mathrm{~kb}$ ). The human SMCR genes are unevenly distributed; 23 genes are in the $\sim 730$-kb interval between the middle SMSREP and SMCR2, and only 7 genes are in the remaining $\sim 400$ kb segment (Fig. 4).

We identified 16 genes (Group I), 6 predicted genes (Group II), and 3 pseudogenes (Group III) in the mouse region syntenic to SMCR (Fig. 4; Table 3); 8 fewer than in the human. Similar to the gene distribution in the human SMCR, the gene density in the region between Shmt1 and Rai1 is higher than in the remaining portion. Comparison of human and mouse sequences indicated that 19 genes in the human SMCR have orthologs in the mouse syntenic region, with conservation of both the order and the orientation, and the same numbers of pseudogenes are present (Fig. 5). Homology is higher across the exons, but extends to some introns and intergenic regions.

Differences in the gene content between the human SMCR and the mouse syntenic region were also observed. RPL13 and 10 predicted genes within the human SMCR are not present within the mouse syntenic region. In the SMCR no genes were identified in the $\sim 20$-kb genomic sequence between LLGL1 and FLJ20308 (Fig. 4); as defined by RepeatMasker, this region consists of 56\% repetitive sequences. In contrast, in the mouse, an $\sim 110-\mathrm{kb}$ genomic region separates Flj20308 and Llglh, two genes, $\mathrm{Ubl}$ and Pabplp, were predicted within this interval (Fig. 4).

Genes $\mathrm{Ubl}$ and Pabplp are homologous to ubiquitin and poly(A)-binding protein, respectively. The human ubiquitin gene subfamily consists of primarily processed pseudogenes (Baker and Board 1992). The poly(A)-binding protein is a conserved protein that binds to the $3^{\prime}$ poly(A) tail on mRNAs in eukaryotic cells (Kleene et al. 1994). Both genes are present as intermixed gene repeating units with seven copies for $U b l$ and 
Table 1. Clinical Features of Patients with Atypical Deletions within 17p11.2

\begin{tabular}{|c|c|c|c|c|c|c|c|c|}
\hline \multirow[b]{2}{*}{ Features $^{a}$} & \multicolumn{6}{|c|}{ SMS $^{b}$} & \multicolumn{2}{|c|}{ Not SMS } \\
\hline & 540 & 1190 & 1456 & 1354 & 1615 & 1774 & 765 & 357 \\
\hline \multicolumn{9}{|l|}{ Craniofacial } \\
\hline Midfacial hypoplasia & + & + & + & + & + & + & + & - \\
\hline Brachycephaly & - & + & - & - & + & + & + & - \\
\hline Broad face & - & + & + & + & + & + & - & - \\
\hline Abnormal ears & - & + & + & - & - & + & - & - \\
\hline Down-turned mouth & + & + & + & + & + & + & - & - \\
\hline \multicolumn{9}{|l|}{ Skeletal } \\
\hline Short, broad hands & + & + & - & + & + & - & + & - \\
\hline Short stature & + & + & + & + & - & + & - & - \\
\hline \multicolumn{9}{|l|}{ Neuro/behavioral } \\
\hline Mental retardation & + & + & + & + & + & + & + & + \\
\hline Speech delay & + & + & + & + & + & + & + & + \\
\hline Motor delay & - & + & + & + & + & + & + & + \\
\hline Sleep disturbance & + & + & + & + & + & + & - & - \\
\hline Self-destructive & + & + & - & + & + & + & - & - \\
\hline Aggressive/tantrums & + & + & + & + & + & + & - & - \\
\hline Self-hugging or hand clasp & $?$ & + & - & + & $?$ & - & - & - \\
\hline \multicolumn{9}{|l|}{ Otolaryngologic } \\
\hline Middle ear & + & - & + & + & - & + & - & - \\
\hline Palatal anomaly/dysfunction & - & - & + & + & - & - & - & NA \\
\hline Age at evaluation & $15 y$ & $26 y$ & $7 \mathrm{y}$ & $7 y$ & $6 y$ & $4 y$ & $17 \mathrm{y}$ & $6 y$ \\
\hline Gender & M & $\mathrm{M}$ & $\mathrm{F}$ & $\mathrm{F}$ & $\mathrm{F}$ & $M$ & M & M \\
\hline
\end{tabular}

four copies for Pabplp (Fig. 4B). Because three copies of each $\mathrm{Ubl}$ and Pabplp could be translated without a premature stop codon, we placed both genes in Group II. In addition, another predicted mouse gene, 1700013G23Rik, is also not located within the human SMCR (Fig. 4).

\section{Genes in the SMCR (Group I)}

We identified 20 genes within the human SMCR (Table 2). Of the 12 genes mapped in 17p11.2, the genomic structures have been described previously for the following 9: NT5M, PEMT, SREBF1, RAI1, DRG2, MYO15A, FLII, TOP3A, and SHMT1. Here we describe the genomic structures of the other 3 genes: LLGL1, TOM1L2, and ATP12. In addition, two known genes: RASD1 and RPL13, and six unknown genes: FLJ10193, DKFZp586M1120, MGC3048, FLJ20308, SMCR7, and SMCR8, are newly mapped to this region (Fig. 6).

Previously, only seven genes in mice: Pemt, Srebp1, Drg2, Myo15, Llglh, Fliih, and Top3a, were mapped within the SMS syntenic region. Of these, the genomic structure of $\mathrm{Drg} 2$ is not known. We describe the gene structure of Rasd1, Rai1, and Drg2, and assemble six unknown mouse genes homologous to human NT5M, FLJ10193, TOM1L2, DKFZp586M1120, MGC3048, and FLJ20308 (Fig. 6).

\section{FLj10193}

The human and mouse FLJ10193 have the same two-exon gene structure (Fig. 6), but the proteins that they encode have only $64 \%$ homology, which is the lowest homology among all genes identified in the SMCR. FLJ10193 is expressed ubiquitously in human and mouse tissues and has a predicted proline-rich region (Fig. 7; Tables 4 and 5).

\section{RASDI}

Mouse Rasd1 is a member of the RAS superfamily, which was induced rapidly by dexamethasone in AtT-20 cells (Kemppainen and Behrend 1998). RASD1 and Rasd1 have the same genomic structure of two exons separated by a $<1-\mathrm{kb}$ intron (Fig. 6).

\section{RAll}

The genomic structure of RAI1 was described recently (Seranski et al. 2001). We found that there are two additional transcripts: KIAA1820 (AB058723) and DKFZp434A139 (AL133649) in an $\sim 130-\mathrm{kb}$ region, which share part of their coding regions with RAI1 (AJ271790; Fig. 6A). A polyglutamine was observed in RAI1 and KIAA1820 but not in DKFZp434A139. Mouse Rai1 contains two exons corresponding to the exons 2 and 3 of transcript KIAA1820 (Fig. 6B). Mouse transcript AK013909, the homolog of DKFZp586M1120, was also identified (Fig. 6B).

\section{TOMIL2}

We assembled TOM1L2 and Tom1l2, the human and mouse homologs of chicken Tom $1 B$, respectively, by multiple EST alignments. Human TOM1L2 shares a similar genomic structure with its mouse homolog (Fig. 6). VHS and GAT domains, which are involved in vesicular trafficking (Lohi and Lehto 1998; Puertollano et al. 2001), are present in both the human and mouse hypothetical proteins. A major $6.0-\mathrm{kb}$ and a minor 2.4-kb transcript were identified in all human tissues examined, with a significantly higher level in the heart and skeletal muscle (Fig. 7A). However, when mouse tissues were analyzed, seven transcripts were observed, and the alternative splicing patterns displayed tissue-specific variations (Fig. 7B).

\section{ATP12}

ATP12 is a human homolog of a yeast nuclear gene required for the assembly of the mitochondrial $\mathrm{F}_{1}$-ATPase (Wang et al. 


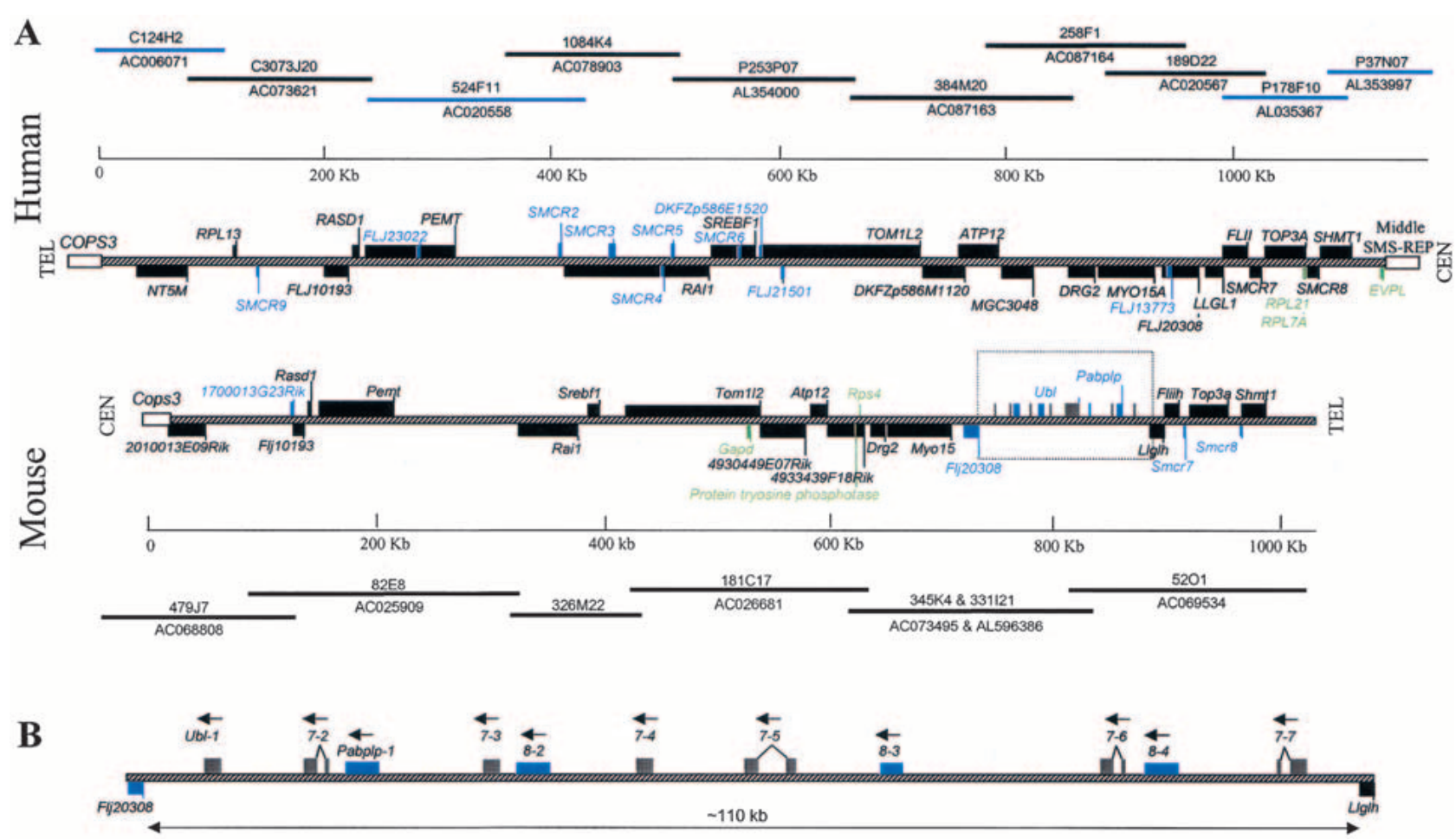

Figure 4 Transcript map of the SMCR and its mouse syntenic region. The BAC and PAC clones are identified by name and accession number. (A) Clones without a prefix are BACs from RPCl-11 (human) or from RPCl-23 (mouse); those with prefix P are PAC clones; those with prefix $\mathrm{C}$ are CTD clones. The hatched line represents the SMCR, and the open boxes represent the flanking sequences of the SMCR: COPS 3 and the middle SMS-REP. The position 0 on the size scale is assigned to the nucleotide proximal to the putative promoter of the COPS3 gene. Genes inside SMCR are represented by black boxes, predicted genes by blue boxes, and pseudogenes by green boxes. The predicted genes Ub/ and Pabplp are located between Flj20308 and Llglh, and both are present as a gene cluster. To distinguish from Pabplp, gray boxes were used to represent the Ubl. Human genes transcribed from centromere to telomere are located above the central line, and genes transcribed from telomere to centromere are below the line. The mouse genes are drawn in the reciprocal manner (i.e., genes transcribed from telomere to centromere are above the central line). (B) The structure of the $\sim 110-\mathrm{kb}$ gene clusters between Flj20308 and Llgh/ that is boxed in A. Seven copies of Ubl and four copies of Pabplp are intermixed. Solid lines connecting exons represent the splicing pattern. All copies are potentially transcribed in the same direction (arrows). The $\mathrm{Ubl}$ gene appears to have four copies with spliced variants.

2001). Alternative splicing is observed for exon 3 , exon 6 , and the last exon (Fig. 6A). The 3'-UTR of ATP12 overlaps with exon 10 of DKFZp586M1120, which encodes the 3'-UTR (Fig. $6 \mathrm{~A})$. However, the corresponding mouse genes are not overlapping.

\section{DKFZp586M1120}

DKFZp586M1120 encodes a putative 225-amino-acid protein (Table 2), in which five leucine-rich repeats (LRR) were identified. LRR-containing proteins often are involved in proteinprotein interactions and cellular adhesion (Rothberg et al. 1990). The putative protein shares $61 \%$ homology with PPP1R7, the human homolog of yeast sds22, a mitotic regulator of protein phosphatase-1. A 1.8-kb transcript was observed predominantly in human kidneys and mouse testes (Fig. 7).

\section{MGC3048}

A putative 217-amino-acid protein encoded by human MGC3048 has the same size as that encoded by its mouse homolog. The two proteins share significant homology with 93\% identity. PipMaker analysis revealed conservation of sequence not only in all exons but also throughout the first intron, which may potentially contain regulatory elements for MGC3048 (data not shown). Ubiquitous expression was observed in both human and mouse tissues (Fig. 7).

\section{FLJ20308}

FLJ20308 contains 4 exons encoding a putative 378-aminoacid transmembrane protein (Fig. 6). This gene is well conserved in the mouse with conservation in all exons, introns, and the promoter region (data not shown). Northern blotting identified two transcripts in both human and mouse tissues (Fig. 7). The expression is observed in all tissues, with relatively higher expression in heart and skeletal muscle.

\section{LLGL1}

Lethal(2) giant larvae is a Drosophila tumor-suppressor gene. Both human and mouse homologs have been described (Tomotsune et al. 1993; Koyama et al. 1996). The overlapping of the $3^{\prime}$ end of $L L G L 1$ with the 3 ' end of FLII is similar to that observed for ATP12 and DKFZp586M1120, but in contrast the LLGL1 and FLII overlap is found in both humans and mice (Campbell et al. 1997, 2000). LLGL1 spans $14.5 \mathrm{~kb}$ with 22 exons and is transcribed toward the centromere (Fig. 6A).

\section{SMCR7}

SMCR7 was represented by a cluster of more than 20 ESTs, and two splicing variants with different 5 '-UTRs were identified 


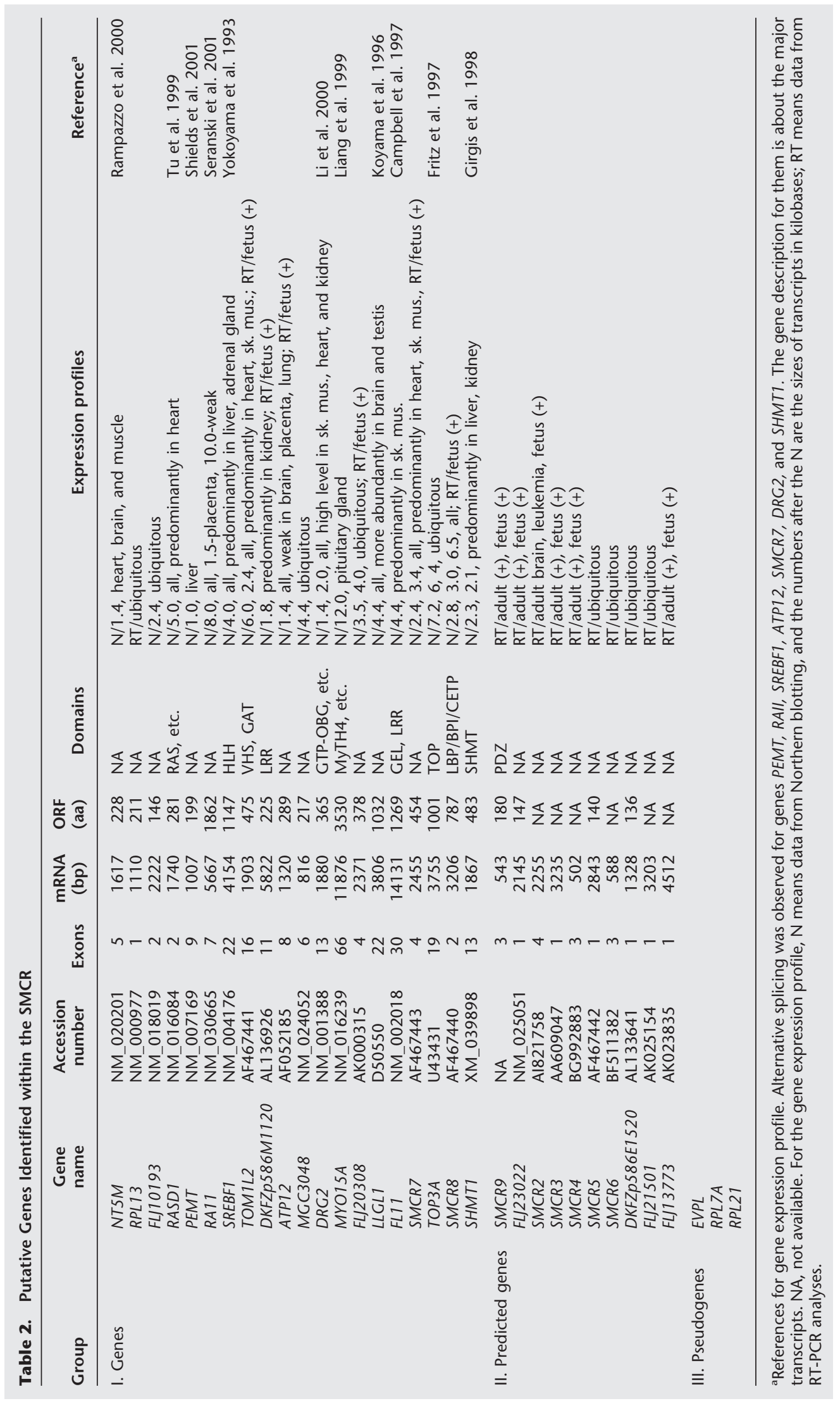




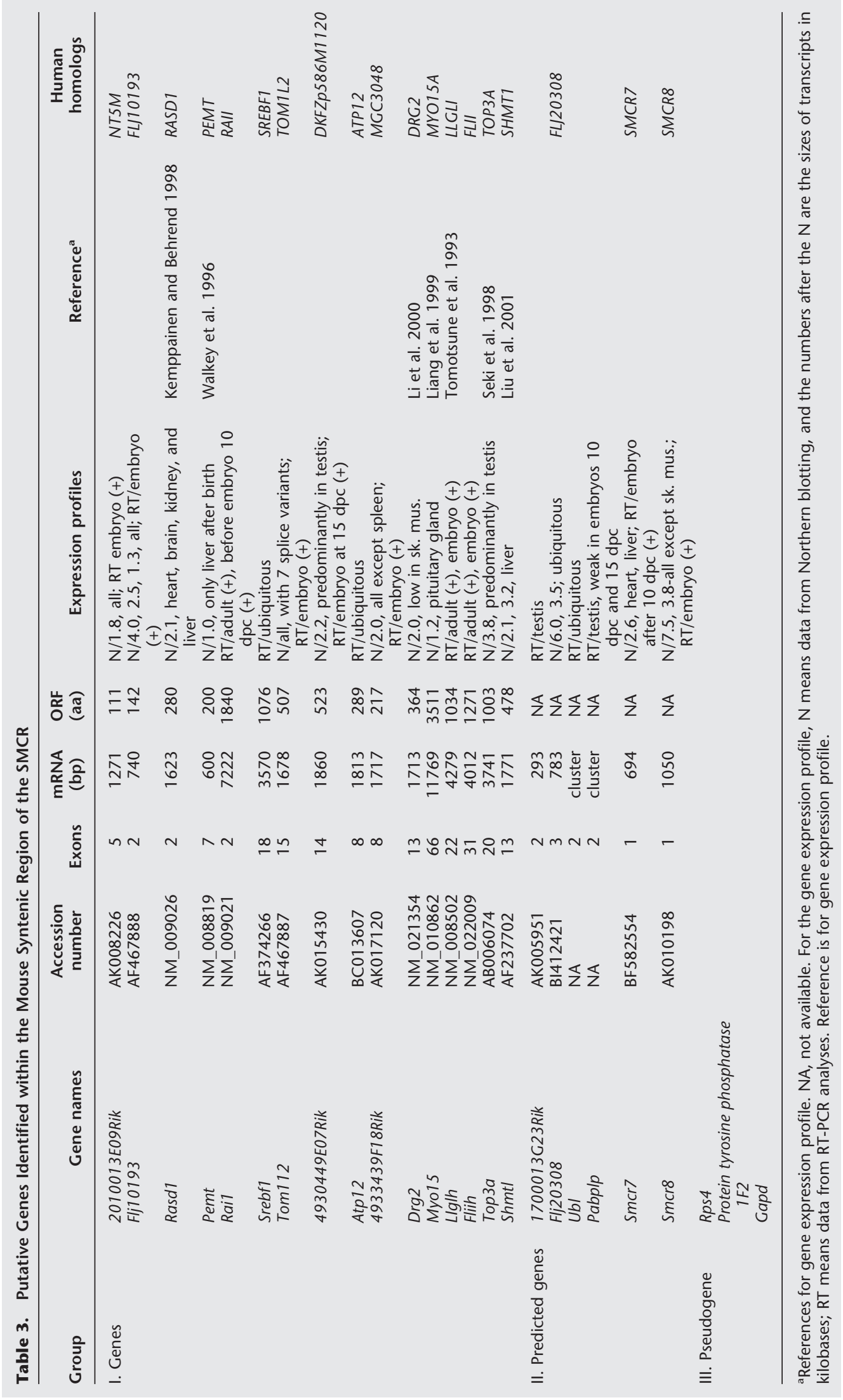




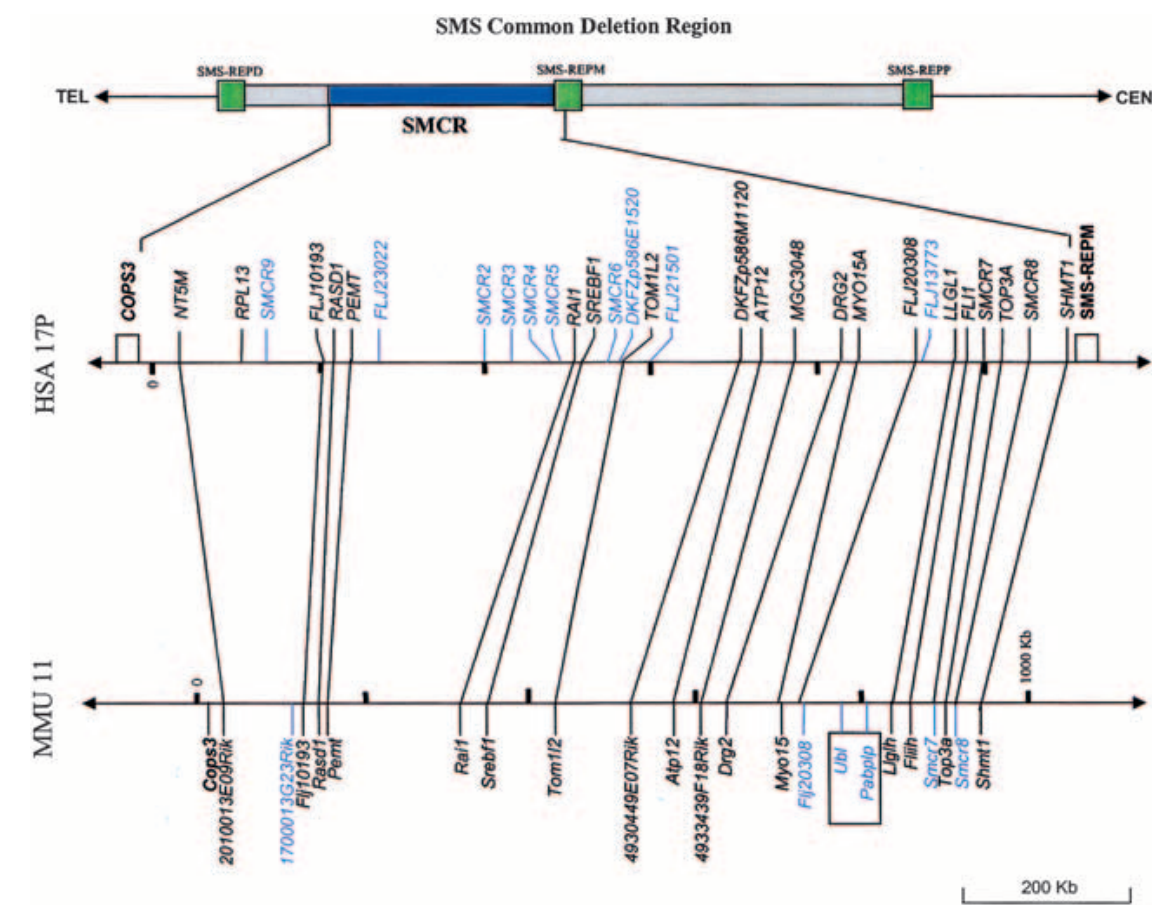

Figure 5 Comparison of the order of the putative genes in the SMCR and the mouse syntenic region. The open boxes represent the flanking sequences of the SMCR: COPS3 and the middle SMS-REP. Genes are in black, and predicted genes are in blue. Genes in the SMCR are connected with their mouse homologs by lines. The region that contains two mouse gene clusters that are not inside the SMCR is boxed. The location of the SMCR in the common deletion region is indicated at the top.

(Fig. 6A). The putative 353-amino-acid transmembrane protein shows no homology to proteins with defined functions. PipMaker analysis revealed sequence conservation throughout the coding region, indicating the presence of the mouse homolog in the syntenic region. We have not obtained the full-length mouse gene, but several mouse ESTs have been identified. Two transcripts were detected by Northern blotting on human tissues with a similar expression pattern, a major 2.8-kb transcript and a minor 3.4-kb transcript, confirming alternative splicing for SMCR7 (Fig. 7A). Both transcripts were expressed ubiquitously with a relatively higher expression level in heart and skeletal muscle.

\section{SMCR8}

A novel gene, SMCR8, was identified between SHMT1 and TOP $3 A$, with its putative promoter only $286 \mathrm{bp}$ proximal to the promoter of TOP3A. SMCR8 contains two exons encoding a putative 787-amino-acid protein that encompasses an $\mathrm{N}$ terminal domain of the LBP/BPI/CETP family involved in lipid binding (Fig. 6; Beamer et al. 1997). More than 75\% homology between human and mouse sequences in its coding region was identified. SMCR8 is expressed in all tissues examined (Tables 4 and 5), and several transcripts were observed in both human and mouse tissues (Fig. 7).

\section{Predicted Genes in the SMCR (Group II)}

Ten predicted genes were identified within the human SMCR (Table 2). The existence of these genes is indicated by the presence of multiple ESTs, poly(A), or intron structure, as well as expression in RT-PCR analysis. Each of the predicted genes has no homologs identified in the syntenic region of the mouse. Seven genes are located inside introns of other genes. This potentially explains why these genes have not been identified by gene prediction programs (Fig. 4). RT-PCR showed that each predicted gene is expressed in almost all adult and fetal tissues examined except SMCR2, which was expressed in the brain, fetal brain, spinal cord, and trachea (Table 4; data not shown). SMCR9 contains two putative PDZ domains, a protein-protein interaction domain likely involved in protein clustering and scaffolding (Sheng and Sala 2001).

\section{Pseudogenes (Group III)}

Three pseudogenes were identified within the SMCR, including EVPL and two adjacent ribosome protein genes, RPL17 and RPL7A. EVPL is located adjacent to the middle SMS-REP and distal to SHMT1, a region with no conservation to the mouse syntenic region as shown by PipMaker. Also, three pseudogenes, Rps4, Gapd, and Protein tyrosine phosphatase IF2, were identified in the mouse syntenic region.

\section{DISCUSSION}

Chromosome 17p11.2 is an unstable genomic region harboring several low-copy repeats associated with genomic disorders (Lupski 1998; Stankiewicz and Lupski 2002). Our comparative analysis between the genomic sequence of the SMS region and the syntenic region on mouse chromosome 11 revealed information regarding genomic architecture. Moreover, we refined the critical region responsible for SMS to a minimum interval. New genes were identified within this refined SMCR as well as its mouse syntenic region.

\section{Physical and Genetic Map Comparisons}

We previously hypothesized that the reduced male recombination frequency at the CMT1A locus may increase the unequal crossing over. This was proposed to result from an extended region of allelic chromosomes without synapse formation to provide an anchor and prevent chromosomal slipping. Indeed, the SMS region shows reduced recombination in both sexes, as might be expected because there is no parent-oforigin preference for the de novo deletion. In the SMS case, the reduced recombination may also reflect interference owing to proximity to the centromere. Nevertheless, it will be interesting to determine if reduced recombination is a general feature of genomic regions that undergo nonallelic homologous recombination.

\section{Genomic Architecture Revealed through Comparative Genomics}

The percentage of low-copy repeats (LCRs), also termed segmental duplications, in the human genome is greater than in other sequenced genomes, such as the fly and worm (Lander et al. 2001; Venter et al. 2001). Three low-copy repeats SMS- 
Bi et al.

A
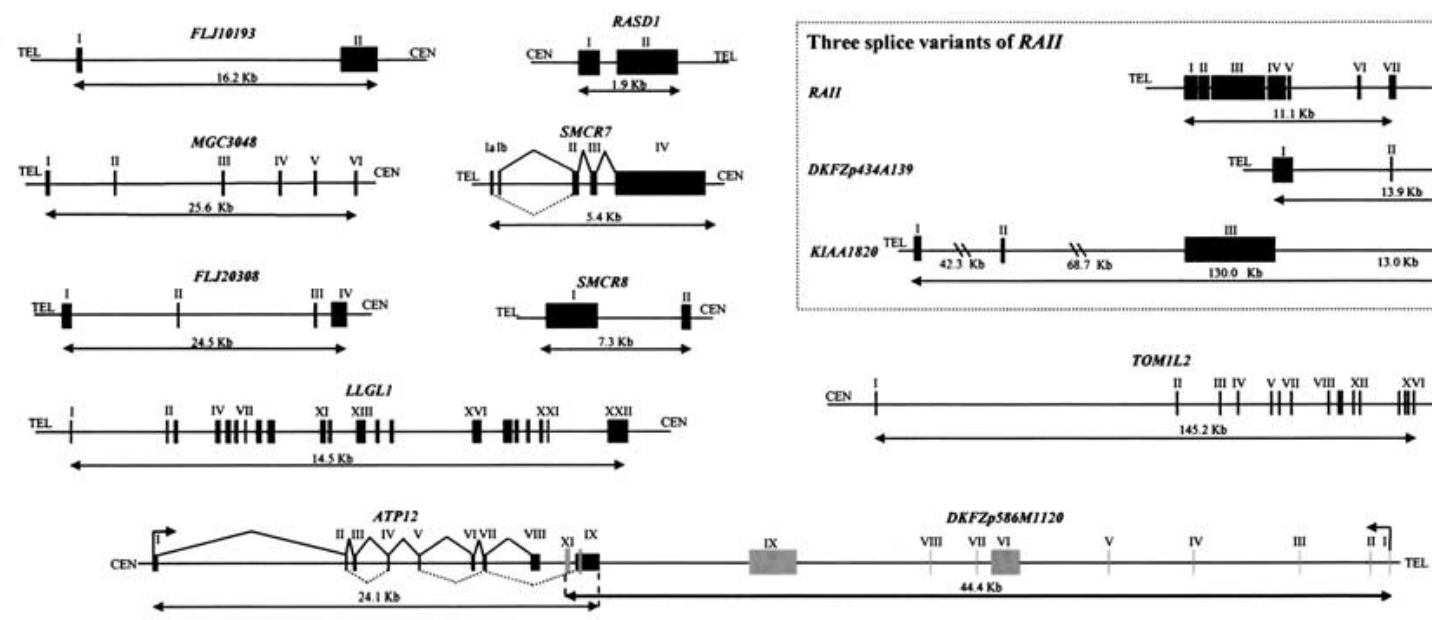

\section{B}
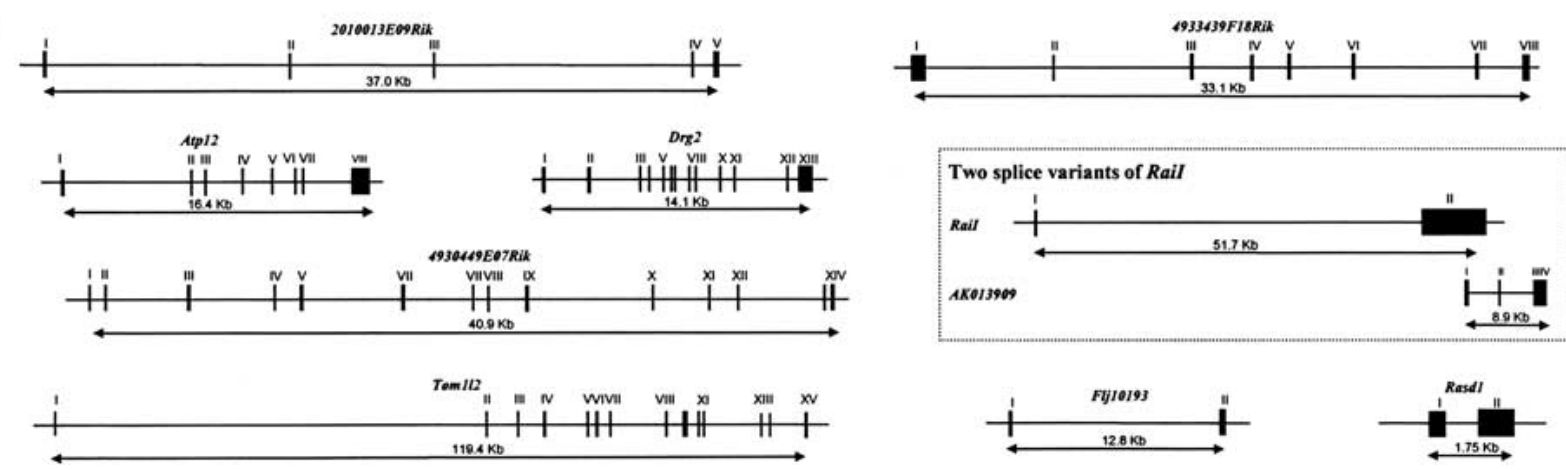

Figure 6 Genomic structure of the genes in the SMCR $(A)$ and in the mouse syntenic region (B). Exons of DKFZp586M1120 are represented by gray boxes; exons of other genes are represented by black boxes. Alternative splicing is observed for RAl1, ATP12, and SMCR7. Dashed lines connecting exons represent the alternative splicing. Exon 10 of DKFZp586M1120 is located inside exon 6 of the ATP12 splice variant. Arrows indicate the orientation of transcription. The introns 2 and 3 of KIAA1820 are not to scale.

REPs on human chromosome $17 \mathrm{p} 11.2$ mediate DNA rearrangements (deletions and duplications) associated with genomic disorders, by nonallelic homologous recombination (Chen et al. 1997; Potocki et al. 2000; Park et al. 2002). Sequence analyses show that all three SMS-REPs within the SMS common deletion are not present in the mouse syntenic region (Fig. 2). Apparently, except for a chromosome inversion of the region between the middle and proximal SMS-REP syntenic region in mouse, the gene order between SMS-REPs is conserved (Fig. 2). Interestingly, transposition occurred for the TACI and KCNJ12 genes adjacent to the SMS-REPs. This rearrangement of gene order might have occurred during the evolution of the SMS-REPs, indicating that segmental duplications might transpose surrounding genes.

Another genome architectural feature revealed by our human/mouse comparative genome analysis is a region containing two intermixed gene repeat units (Fig. 4B). Four of the $\mathrm{Ubl}$ copies retain a putative intron. The four Pabplp copies are interspersed among the $\mathrm{Ubl}$ copies. How this complex array evolved is not immediately obvious, but this entire segment is absent in the human genome.

\section{Gene Density and Evolution}

The gene density of the human SMCR is higher than the es- timated average in the human genome. Within an $\sim 1.1-\mathrm{Mb}$ interval, 19 genes are also present in the same order and orientation in the mouse chromosome (Fig. 5). Highly conserved orthologous regions can contain a high gene density. The number, order, and orientation of all 17 genes in a gene-rich cluster at human 12p13 are conserved between humans and mice (Ansari-Lari et al. 1998). Conservation between these two species was also shown for the distal $700 \mathrm{~kb}$ of the Cat eye syndrome (tetrasomy of 22q11.2) critical region and for human chromosome $11 \mathrm{p} 15.3$, both of which are gene-rich regions (Amid et al. 2001; Footz et al. 2001). According to the mosaic model of genomic evolution, different portions of the genome evolve at different rates (Koop 1995). Thus, gene-rich regions in the genome might have evolved much more slowly than the gene-poor regions.

None of the 10 predicted genes in the SMCR was found in mice. Most of these predicted genes match multiple homologous ESTs. Their existence was further confirmed by their expression in RT-PCR analysis. These genes might have important functions for silencing gene expression as an antisense RNA (Nellen and Lichtenstein 1993). However, the fact that seven predicted genes are located inside introns of other genes indicates that these predicted genes could represent differentially spliced exons or untranslated exons. Therefore, the

\section{Genome Research www.genome.org}


A

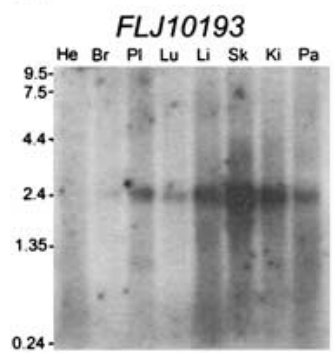

ATP12

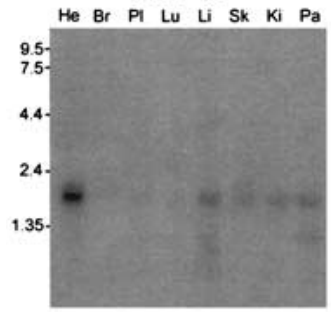

SMCR7

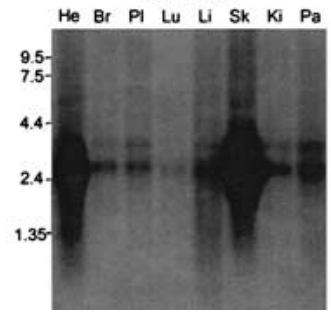

B

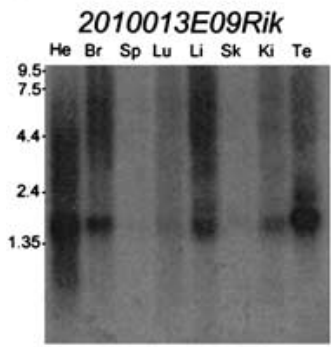

4930449E07Rik

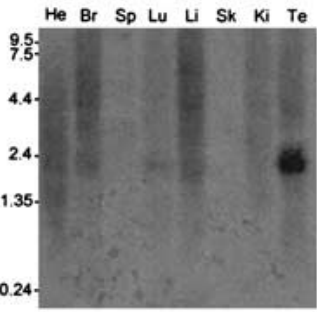

Smcr7

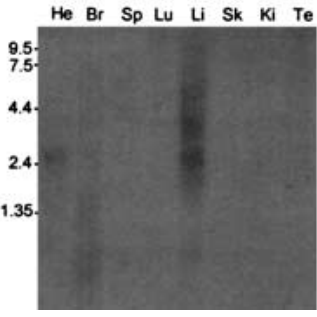

DKFZp586M1120

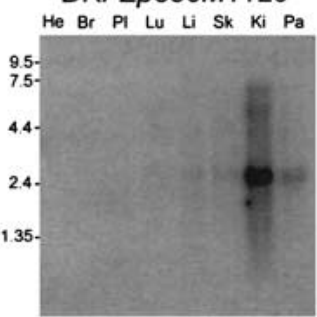

MGC3048

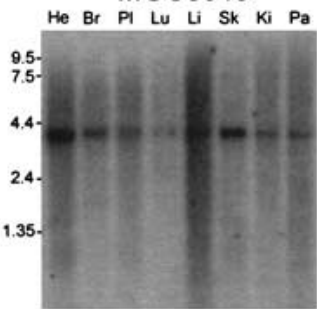

SMCR8

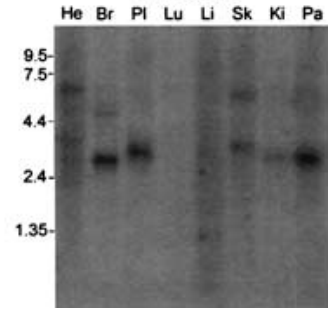

Flj10193

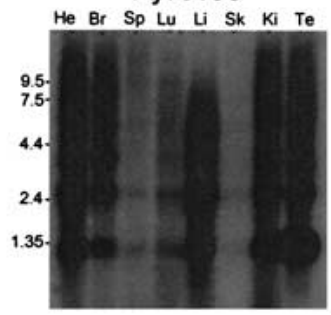

4933439F18Rik

He Br Sp Lu Li Sk Ki To

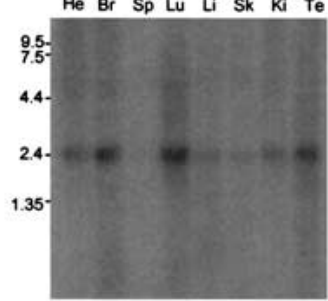

Smcr8

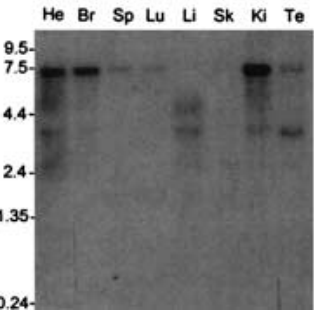

TOM1L2

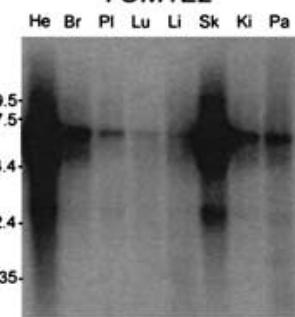

FLJ20308

He Br PI Lu Li Sk Ki Pa

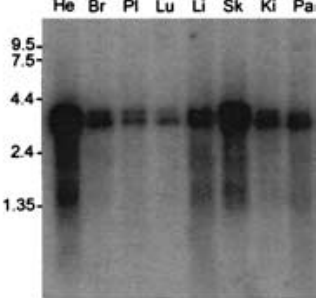

Actin

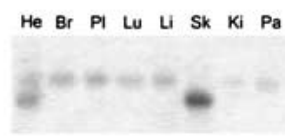

Tom $1 / 2$

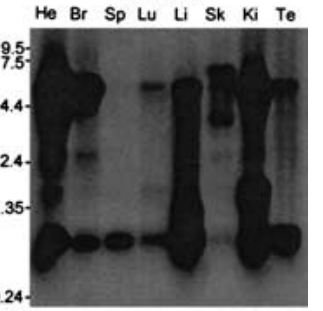

Flj20308

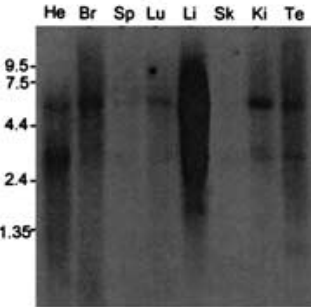

Actin

He Br Sp Lu Li Sk Ki Te

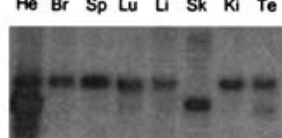

absence of these predicted genes in mice could be due to less alternative splicing. In humans, an alternative-spliced last exon of ATP12 overlaps DKFZp586M1120; however, no alternative splicing was observed for mouse Atp12, and the two corresponding mouse homologs are separated from each other.

\section{A Newly Defined SMS Critical Interval}

Analyses of the deleted intervals of the SMS patients with smaller-sized deletions enabled refinement of the SMS critical region (Fig. 1). Six SMS patients-540, 1190, 1456, 1354, 1615 , and 1774 -were determined to harbor unusual deletions in $17 \mathrm{p} 11.2$. The same deletions were identified for patients 1190 and 1456; but some SMS features such as brachycephaly; short, broad hands; and selfdestructive and self-hugging behavior are present in 1190 but not in 1456. Slightly different phenotypes were also observed for patients 1615 and 1774 with the same deletions. Thus, genetic background and/or stochastic factors may contribute to penetrance of the phenotype. However, because the major SMS features including craniofacial, skeletal, and neuro/behavioral phenotypes were present in two or more patients (Table 1), we determined that the smallest overlap among these patients is the SMCR and that the genes that contribute to the craniofacial, skeletal, and neuro/ behavioral features are likely located within this genomic region.

Two patients, 357 and 765, with an unusual deletion in 17p11.2 have atypical clinical features. The deletions for both 357 and 765 include part of the region between the distal SMS-REP and the middle SMS-REP, with the proximal breakpoints located inside the SMCR. Further study of the breakpoint of patient 765 using a somatic hybrid cell line indicated that it is located inside RP11-258F1, $\sim 210 \mathrm{~kb}$ away from the middle SMS-REP. Because patient 765 does not manifest SMS, it is possible that genes responsible for SMS are located within this $\sim 210 \mathrm{~kb}$ (Fig. 1).

\section{Candidate Genes for the SMS Phenotype}

To delineate genes that contribute to the SMS features, we identified and characterized genes

Figure 7 Northern blotting of the genes in the SMCR $(A)$ and the genes in its mouse syntenic region $(B)$. Tissues are indicated at the top of each lane, and the size markers in kilobases $(\mathrm{kb})$ are the numbers beside the blots. $(\mathrm{He})$ heart; $(\mathrm{Br})$ brain; $(\mathrm{PI})$ placenta; (Lu) lung; (Li) liver; (Sk) skeletal muscle; (Ki) kidney; $(\mathrm{Pa})$ pancreas; (Te) testis. For mRNA quantity, $\beta$-actin was probed as a control. Ubiquitous expression was observed for FLJ10193, MGC3048, FLI20308, and SMCR7. Tissue-specific various-sized transcripts were observed for TOM1L2 and SMCR8. DKFZP586M1120 is predominantly expressed in the kidney, whereas 4930449E07Rik is in the testis. 
Table 4. RT-PCR Analysis of the Genes within the SMCR

\begin{tabular}{|c|c|c|c|c|c|c|c|c|c|c|c|c|c|c|c|c|c|c|c|c|c|c|c|c|}
\hline \multirow[b]{2}{*}{ Gene name } & \multicolumn{16}{|c|}{ Adult } & \multicolumn{8}{|c|}{ Fetal } \\
\hline & B & H & K & Li & Lu & $\mathrm{Pa}$ & PI & Sm & C & Le & 0 & $\mathrm{Pr}$ & Si & Sp & $\mathrm{Te}$ & Th & B & $\mathrm{H}$ & $\mathrm{K}$ & Li & Lu & Sm & Sp & Th \\
\hline SMCR9 & + & + & + & + & + & + & + & + & + & - & w & + & + & + & w & w & + & + & + & w & w & w & - & w \\
\hline FLJ10193 & + & + & + & + & + & + & - & + & + & + & + & + & + & + & + & + & + & + & + & + & + & + & + & + \\
\hline FLJ23022 & + & + & + & + & + & + & - & + & w & + & + & + & + & + & + & + & w & w & + & + & w & $w$ & - & - \\
\hline SMCR2 & + & - & - & - & - & - & - & - & - & + & - & - & - & - & w & - & - & - & - & - & w & - & w & w \\
\hline SMCR3 & - & + & + & w & + & + & w & $w$ & - & + & w & w & - & - & + & - & w & w & + & w & w & w & - & w \\
\hline SMCR4 & - & + & + & w & - & + & - & - & - & - & - & w & - & $w$ & $w$ & + & + & + & + & w & - & - & w & w \\
\hline SMCR5 & + & + & + & + & + & + & w & + & + & + & + & + & + & + & + & + & + & w & + & w & w & w & + & + \\
\hline TOM1L2 & + & + & + & + & + & + & + & + & + & + & + & + & + & + & + & + & + & + & + & + & + & + & w & w \\
\hline SMCR6 & + & + & + & + & + & + & + & + & + & + & + & + & + & + & + & + & + & + & + & + & + & + & + & + \\
\hline FLJ21501 & + & + & + & + & + & + & + & + & + & + & + & + & + & + & + & + & + & + & + & + & + & + & + & w \\
\hline DKFZp586M1120 & - & - & + & + & + & + & - & - & - & - & w & w & - & - & - & - & w & w & + & - & + & - & w & w \\
\hline ATP12 & + & + & + & + & + & + & + & + & + & + & + & - & + & + & - & + & + & + & + & + & + & + & + & + \\
\hline MGC3048 & + & + & + & + & + & + & + & + & + & + & + & + & + & + & + & + & + & + & + & + & + & + & + & + \\
\hline FLJ20308 & + & + & + & + & + & + & + & + & + & + & + & + & + & + & + & + & + & + & + & + & + & + & + & + \\
\hline FLJ13773 & - & + & + & w & + & + & - & - & w & + & + & + & + & + & + & + & + & + & + & + & + & - & + & w \\
\hline SMCR7 & + & + & + & + & + & + & + & + & + & + & + & w & + & + & w & + & + & + & + & + & + & + & + & + \\
\hline SMCR 8 & + & + & + & + & + & + & + & + & + & + & + & + & + & + & + & + & + & - & + & + & + & + & + & + \\
\hline
\end{tabular}

Adult or fetal tissues used are indicated on the top line. $\mathrm{B}$, brain; $\mathrm{H}$, heart; $\mathrm{K}$, kidney; Li, liver; Lu, lung; $\mathrm{Pa}$, pancreas; PI, placenta; Sm, smooth muscle; C, colon; Le, leukemia; O, ovary; Pr, prostate; Si, small intestine; Sp, spleen; Te, testis; Th, thymus; Sp, spleen; +, positive expression; $\mathrm{w}$, very weak expression; -, no expression.

within the SMCR. SMS patients manifest abnormalities in multiple tissues/organs including: neural (100\% mental retardation, 100\% self-hugging, 75\% peripheral neuropathy, and $69 \%$ sleep disorder), eyes (68\% iris abnormalities), ears (81\% hearing impairment), hearts (29\%), kidneys (28\%), and skeletal (93\% midface hypoplasia and $85 \%$ brachydactyly) (Chen et al. 1996). The SMS-causing genes are therefore likely expressed in multiple tissues. With the exception of PEMT and MYO15A, all genes mapped within the SMCR are widely expressed in multiple tissues.

The genes that are responsible for the SMS phenotype are located within the SMCR and are probably dosage-sensitive.
One way to evaluate whether a gene manifests haploinsufficiency effects is by the evaluation of animal models, for example, mice. Until now, targeted disruption of five mouse genes: Pemt, Srebp1, Myo15, Top3a, and Fliih, within SMCR has been reported. The normal heterozygous mutant mice indicated that these genes are not haploinsufficient (Walkey et al. 1996; Shimano et al. 1997; Li and Wang 1998; Probst et al. 1998; H. Campbell, pers. comm.) and therefore are less likely to contribute to the SMS phenotypes. However, dosage sensitivity for a given gene in humans does not necessarily correlate with haploinsufficiency in mice. For example, haploinsufficiency of GATA3 is the underlying mechanism for the

Table 5. RT-PCR Analysis of the Genes within the Mouse Syntenic Region of the SMCR

\begin{tabular}{|c|c|c|c|c|c|c|c|c|c|c|c|c|}
\hline \multirow[b]{2}{*}{ Gene name } & \multicolumn{8}{|c|}{ Adult } & \multicolumn{4}{|c|}{ Embryo } \\
\hline & B & H & K & Li & Lu & Sm & $\mathrm{Sp}$ & $\mathrm{Te}$ & E7 & E10 & E15 & E17 \\
\hline 2010013 E09Rik & + & + & + & + & + & + & w & + & + & + & + & + \\
\hline $1700013 \mathrm{G} 23 \mathrm{Rik}$ & w & w & w & - & w & w & w & + & - & - & - & - \\
\hline Flj10193 & + & + & + & + & + & + & w & + & + & + & + & + \\
\hline Rasd1 & w & w & w & - & w & w & - & + & - & - & - & - \\
\hline Rail & w & - & w & w & w & w & w & w & + & + & - & - \\
\hline Srebfl & + & + & + & + & + & + & + & + & + & w & w & w \\
\hline Tom $1 / 2$ & + & - & + & + & + & + & + & + & + & + & + & + \\
\hline 4930449E07Rik & w & w & - & - & + & - & - & + & - & - & + & + \\
\hline Atp12 & + & + & + & + & + & + & + & + & + & + & + & + \\
\hline 4933439F18Rik & + & + & + & + & + & w & + & + & - & + & + & + \\
\hline Flj20308 & + & + & + & + & + & + & w & + & - & + & + & + \\
\hline Ubl & + & + & + & + & + & + & + & + & - & + & + & + \\
\hline Pabplp & - & - & - & - & - & - & - & + & - & w & w & - \\
\hline Llglh & + & + & - & + & + & + & + & + & + & + & + & + \\
\hline Fliih & + & + & + & + & - & + & + & + & - & + & + & + \\
\hline Smcr7 & + & + & w & + & + & + & - & + & - & + & w & + \\
\hline Smcr8 & + & + & + & + & + & + & + & + & + & + & + & + \\
\hline
\end{tabular}

B, brain; H, heart; K, kidney; Li, liver; Lu, lung; Sm, smooth muscle; Sp, spleen; Te, testis; E7, E10, E15, E17, embryo at 7, 10, 15, 17 dpc. +, positive expression; $w$, very weak expression; - , no expression. 
hypoparathyroidism, sensorineural deafness, and renal anomalies (HDR) syndrome. Mice heterozygous for the Gata3 mutation appear to be normal (Pandolfi et al. 1995; Van Esch and Devriendt 2001). We can also exclude MYO15A because the heterozygous individual carrying this recessive deafness gene does not show SMS (Wang et al. 1998; Liburd et al. 2001).

One potential SMS candidate gene is LLGL1, the human homolog of lethal giant larvae ( $L g l)$, a tumor-suppressor gene in Drosophila. LLGL1 is expressed ubiquitously, with the most abundant expression in the brain and testis (Koyama et al. 1996). Moreover, $L g l$ in Drosophila is essential for asymmetric cortical localization of basal determinants in mitotic neuroblasts, and is required for neural fate decisions (Ohshiro et al. 2000; Peng et al. 2000). Another SMS candidate is RAI1. Mouse Rai1 has neuron-specific expression in the brain and is induced by retinoic acid, which is involved in craniofacial development (Imai et al. 1995; Helms et al. 1997; Padmanabhan and Ahmed 1997). Therefore, haploinsufficiency of RAI1 may account for both neuro/behavioral abnormalities and facial abnormalities in SMS. Two GTP-binding proteins were identified within the SMCR: DRG2 and RASD1. DRG2 is a developmentally regulated protein, and is closely related to DRG1 (Li and Trueb 2000). RASD1 is a brain-enriched G protein that is strongly and rapidly induced during treatment with dexamethasone (Kemppainen and Behrend 1998). Both the LRR in DKFZp586M1120 and the PDZ domain in SMCR9 are associated with protein-protein interaction. Genes involved in signal transduction or protein-protein interactions have the potential to show haploinsufficiency effects, because half dosage may affect the balance of protein complexes, and then interfere with a series of related events required for normal development. The three genes FLJ20308, SMCR7, and SMCR8 located within the $\sim 210$-kb region also remain promising SMS candidates, although we have no clues as to their functions. Targeted mutation of these genes will help unravel their potential roles in SMS.

\section{One or More SMS-Causing Genes?}

It is unclear whether haploinsufficiency of either one single gene or several contiguous genes causes the characteristic features of SMS as classically proposed (Schmickel 1986; Shaffer et al. 2001). The causative genes for several microdeletion syndromes have been identified. In some syndromes, haploinsufficiency of a single gene is responsible for the entire phenotype. The Rubinstein-Taybi syndrome (RTS), associated with microdeletion of $16 \mathrm{p} 13.3$, consists of facial abnormalities, broad thumbs, broad big toes, and mental retardation. Loss of one functional copy of a transcriptional coactivator cyclic AMP response-element-binding protein, (CREB)binding protein $(C B P)$, underlies all the developmental abnormalities in RTS (Petrij et al. 1995). This was clearly documented by identifying patients with $C B P$ null alleles caused by frameshift or nonsense mutations. Another example of a monogenic microdeletion syndrome is Alagille syndrome, sometimes associated with the deletion of 20p12. The causative gene for all the features of this syndrome is JAG1, which encodes a ligand for Notch1 (Li et al. 1997; Oda et al. 1997).

Because deletions of genomic regions inside $17 \mathrm{p} 11.2$ are identified in almost all SMS patients, it is possible that haploinsufficiency of more than one gene underlies the SMS phenotype. In some contiguous gene-deletion syndromes, mutation in one gene accounts for only a portion of the phenotype
(Shaffer et al. 2001). For example, deletion of the elastin gene, $E L N$, leads to vascular stenoses, one of the clinical features of Williams syndrome (WS), a developmental disorder caused by a deletion of band 7q11.23 (Ewart et al. 1993). The specific gene(s) for other features of WS including growth retardation, hypercalcemia, renal anomalies, and mental retardation are still unknown (Ewart et al. 1993). Miller-Dieker syndrome (MDS) is a multiple malformation syndrome characterized by lissencephaly and facial abnormalities (Dobyns et al. 1984). LIS1, the gene inside the MDS critical region, encodes a subunit of the brain platelet-activating factor acetylhydrolase $(P A F A H)$, and is responsible only for brain malformation (Hirotsune et al. 1998; Pilz et al. 1998). The additional features such as facial abnormalities are thought to be caused by other unknown genes. Therefore, to identify the genes involved in manifesting phenotypes of a contiguous gene deletion syndrome, an important step is to determine the finished sequence of the genomic region corresponding to the deleted interval, and identify all the genes within that region.

\section{Conclusions}

We have refined the critical SMS interval to an $\sim 1.1-\mathrm{Mb}$ genomic region and performed gene identification and characterization for this newly defined critical region and its syntenic region in the mouse. Our data provide insights into genome architecture and evolution, and new genomic information for comparative analysis between humans and mice, indicate potential SMS candidate genes, facilitate the identification of the haploinsufficient genes involved in this syndrome, and provide information necessary for engineering a mouse model of SMS.

\section{METHODS}

\section{Construction of BAC/PAC Contig}

CTD and PAC clones were selected from the NCBI database (http://www.ncbi.nlm.nih.gov) based on their sequence homology with the STS markers mapped inside the SMS common deletion region. The BAC clones were isolated by radioactive filter hybridization of human RPCI-11 and mouse RPCI-23 BAC libraries (BACPAC Resources) using probes to STS markers. BAC end sequences were determined either from the database (http://www.tigr.org) or by direct sequencing. The extent of the genomic clones was determined by STS content mapping. Gaps were filled by multipoint walking based on end sequences of several selected BACs.

Up to 20 oligonucleotide overgo probes (Cai et al. 1998) were included in one hybridization, and positive clones were identified by PCR using primers derived from the parental clone ends. The location of each BAC in the SMCR was further confirmed by FISH on cells from SMS patient lymphoblasts. Human BACs for the minimum tiling paths were submitted to the Whitehead Institute for Biomedical Research at the Massachusetts Institute of Technology. Mouse BACs were submitted to the Human Genome Sequencing Center at Baylor College of Medicine or the Sanger Center for sequencing.

\section{Refining the SMCR}

The SMCR was refined by FISH on lymphoblast cell lines derived from SMS patients with unusual smaller deletions. BAC/PAC DNA was prepared using the PSI Clone BAC DNA kit (Princeton Separations, Inc.) or the Plasmid Midi Kit (QIAGEN) according to manufacturers' instructions. The DNA probe $(1 \mu \mathrm{g})$ was labeled by nick-translation using biotin (Life Technologies-GIBCO BRL) or digoxigenin (Boehringer Mannheim). Biotin was detected with FITC-avidin DCS (Vector 
labs), and digoxigenin was detected with rhodamine-antidigoxigenin antibodies (Sigma). Chromosomes were counterstained with DAPI diluted in Vectashield antifade (Vector Labs). Cells were viewed under a Zeiss Axioskop fluorescence microscope.

\section{Informatics}

Sequencher 3.1 software (Gene Codes) was used for sequence alignment, DNA translation, and annotation. Human and mouse interspersed repeat sequences were detected and masked using RepeatMasker (http://ftp.genome.washington. edu/cgi-bin/RepeatMasker). DNA sequences were separated into $\sim 50-\mathrm{kb}$ segments and analyzed using the NIX analysis (http://www.hgmp.mrc.ac.uk/Registered/Webapp/nix); an integrated Web-based multiple DNA analysis bioinformatics tool including GRAIL, Fex, Hexon, MZEF, Genemark, GeneFinder, FGENES, Polyah, RepeatMasker, tRNAscan, and BLAST, that searches many databases. Potential genes were further analyzed individually using FGENES (http:// genomic.sanger.ac.uk/gf/gfb.html) for gene structure and $\mathrm{ORF}$ Finder (http://www.ncbi.nlm.nih.gov/gorf) for translation and ORFs. The putative proteins were analyzed using P fam 6.6 (http://pfam.wustl.edu), InterPRO (http://www.ebi.ac.uk/ interpro) for domains, and TMpred (http://www.ch. embnet.org/software/TMPRED_form.html) for transmembrane regions.

DNA and protein sequence similarity was analyzed with BLAST (http://www.ncbi.nlm.nih.gov/BLAST) against the nr, EST, and htgs databases using the default parameters. Human noncontinuous DNA sequences proximal to COPS3 and distal to the middle SMS-REP, corresponding to the SMCR, were repeat-masked and compared with mouse noncontinuous DNA sequences of five BACs (a gap between RP23-82E8 and RP23-181C17 was filled using Celera's genome sequences) using the PipMaker program (http://bio.cse.psu.edu/pipmaker/). PipMaker computes alignments of similar regions in two DNA sequences, and the resulting alignments are summarized with a percent identity plot (PIP; Schwartz et al. 2000).

\section{RT-PCR Analyses and Northern Blotting}

Gene expression profiles in human and mouse tissues were analyzed by Northern blotting (Fig. 7) and/or RT-PCR (Tables 4 and 5). RT-PCR analyses were performed using the firststrand cDNA from various adult and fetal tissues (Clontech). Primers were designed using Primer3 (http://wwwgenome.wi.mit.edu/genome_software/other/primer1.html). Hotstart DNA polymerase (QIAGEN) was used to reduce the amplification of nonspecific PCR products; PCR conditions consisted of $95^{\circ} \mathrm{C}$ for $15 \mathrm{~min}, 1$ cycle; $95^{\circ} \mathrm{C}$ for $30 \mathrm{sec}, 60^{\circ} \mathrm{C}$ for $30 \mathrm{sec}, 72^{\circ} \mathrm{C}$ for $1 \mathrm{~min}, 32$ cycles; and a final extension cycle at $72^{\circ} \mathrm{C}$. There was no amplification of genomic untranscribed sequences consistent with the absence of genomic DNA contamination in both human and mouse cDNAs. For Northern blotting, probes were designed to DNA sequences of the $3^{\prime}$ UTR of each gene. Radioactive hybridization was performed on multiple tissue blots following the manufacturer's instructions (Clontech).

\section{NOTE ADDED IN PROOF}

While our manuscript was under review, a paper regarding analysis of a human genomic contig and a transcription map of the SMS critical interval was published (Lucas et al. 2001). Comparison of the gene lists within our SMCR indicated that 15 genes or ESTs (NT5M, FLJ10193, RASD1, PEMT, RAI1, SREBF1, TOM1L2, ATP12, MGC3048, DRG2, MYO15A, LLGL1, FLII, TOP $3 A$, and SHMT1) were identified in both papers, and 5 genes (RPL13, DKFZp586M1120, FLJ20308, SMCR7, and SMCR8) and 10 predicted genes (SMCR9, FLJ23022, SMCR2, SMCR3, SMCR4, SMCR5, SMCR6, DKFZp586E1520, FLJ21501, and FLJ13773) described in this paper are not mentioned in the Lucas paper. One gene (EEF1A3) and 4 ESTs (IB1187, stSG8339, stSG9692, and T78887) reported in the Lucas paper are not included in this paper because the information available was not sufficient to identify them as genes.

\section{ACKNOWLEDGMENTS}

We appreciate the critical reviews of B.A. Bejjani and N. Katsanis and the technical assistance of M. Withers. We thank B. Birren and K. Dewar of Whitehead Institute for Biomedical Research/MIT Center for Genome Research for contributing many thoughtful discussions. S.-S.P. was supported by a fellowship from the South Korean government, and K.I. by postdoctoral fellowships from the Charcot-Marie-Tooth Association and the Muscular Dystrophy Association. This research was supported in part by grants from the Muscle Dystrophy Association, the National Institute of Child Health and Human Development (P01 HD38420), the National Institute of Neurological Disorders and Stroke (R01 NS27042), and the National Cancer Institute (P01 CA75719).

The publication costs of this article were defrayed in part by payment of page charges. This article must therefore be hereby marked "advertisement" in accordance with 18 USC section 1734 solely to indicate this fact.

\section{REFERENCES}

Amid, C., Bahr, A., Mujica, A., Sampson, N., Bikar, S-E., Winterpacht, A., Zabel, B., Hankeln, T., and Schmidt, E.R. 2001. Comparative genomic sequencing reveals a strikingly similar architecture of a conserved syntenic region on human chromosome 11p15.3 (including gene ST5) and mouse chromosome 7. Cytogenet. Cell Genet. 93: 284-290.

Ansari-Lari, M.A., Oeltjen, J.C., Schwartz, S., Zhang, Z., Muzny, D.M., Lu, J., Gorrell, J.H., Chinault, A.C., Belmont, J.W., Miller, W., et al. 1998. Comparative sequence analysis of a gene-rich cluster at human chromosome 12 p13 and its syntenic region in mouse chromosome 6. Genome Res. 8: $29-40$.

Baker, R.T. and Board, P.G. 1992. The human ubiquitin/52-residue ribosomal protein fusion gene subfamily $\left(\mathrm{UbA}_{52}\right)$ is composed primarily of processed pseudogenes. Genomics 14: 520-522.

Beamer, L.J., Carroll, S.F., and Eisenberg, D. 1997. Crystal structure of human BPI and two bound phospholipids at 2.4 angstrom resolution. Science 276: 1861-1864.

Cai, W.-W., Reneker, J., Chow, C.-W., Vaishnav, M., and Bradley, A. 1998. An anchored framework BAC map of mouse chromosome 11 assembled using multiplex oligonucleotide hybridization. Genomics 54: 387-397.

Campbell, H.D., Fountain, S., Young, I.G., Claudianos, C., Hoheisel, J.D., Chen, K.-S., and Lupski, J.R. 1997. Genomic structure, evolution, and expression of human FLII, a gelsolin and leucine-rich-repeat family member: Overlap with $L L G L$. Genomics 42: $46-54$.

Campbell, H.D., Fountain, S., Young, I.G., Weitz, S., Lichter, P., and Hoheisel, J.D. 2000. Fliih, the murine homologue of the Drosophila melanogaster flightless I gene: Nucleotide sequence, chromosomal mapping and overlap with Llglh. DNA Seq. 11: $29-40$.

Chen, K.-S., Potocki, L., and Lupski, J.R. 1996. The Smith-Magenis syndrome [del(17)p11.2]: Clinical review and molecular advances. MRDD Res. Rev. 2: 122-129.

Chen, K.-S., Manian, P., Koeuth, T., Potocki, L., Zhao, Q., Chinault, A.C., Lee, C.C., and Lupski, J.R. 1997. Homologous recombination of a flanking repeat gene cluster is a mechanism for a common contiguous gene deletion syndrome. Nat. Genet. 17: $154-163$.

Chevillard, C., Le Paslier, D., Passage, E., Ougen, P., Billault, A., Boyer, S., Mazan, S., Bachellerie, J.P., Vignal, A., Cohen, D., et al. 1993. Relationship between Charcot-Marie-Tooth 1A and Smith-Magenis regions. snU3 may be a candidate gene for the Smith-Magenis syndrome. Hum. Mol. Genet. 2: 1235-1243.

Dobyns, W.B., Stratton, R.F., and Greenberg, F. 1984. Syndromes with lissencephaly. I: Miller-Dieker and Norman-Roberts syndromes and isolated lissencephaly. Am. J. Med. Genet. 18: $509-526$.

Dunham, I., Shimizu, N., Roe, B.A., Chissoe, S., Hunt, A.R., Collins, J.E., Bruskiewich, R., Beare, D.M., Clamp, M., Smink, L.J., et al. 
1999. The DNA sequence of human chromosome 22. Nature 402: 489-495.

Elsea, S.H., Purandare, S.M., Adell, R.A., Juyal, R.C., Davis, J.G., Finucane, B., Magenis, R.E., and Patel, P.I. 1997. Definition of the critical interval for Smith-Magenis syndrome. Cytogenet. Cell Genet. 79: 276-281.

Ewart, A.K., Morris, C.A., Atkinson, D., Jin, W., Sternes, K., Spallone, P., Stock, A.D., Leppert, M., and Keating, M.T. 1993. Hemizygosity at the elastin locus in a developmental disorder, Williams syndrome. Nat. Genet. 5: 11-16.

Footz, T.K., Brinkman-Mills, P., Banting, G.S., Maier, S.A., Riazi, M.A., Bridgland, L., Hu, S., Birren, B., Minoshima, S., Shimizu, N., et al. 2001. Analysis of the Cat Eye Syndrome critical region in humans and the region of conserved synteny in mice: A search for candidate genes at or near the human chromosome 22 pericentromere. Genome Res. 11: 1053-1070.

Fritz, E., Elsea, S.H., Patel, P.I., and Meyn, M.S. 1997. Overexpression of a truncated human topoisomerase III partially corrects multiple aspects of the ataxia-telangiectasia phenotype. Proc. Natl. Acad. Sci. 94: 4538-4542.

Girgis, S., Nasrallah, I.M., Suh, J.R., Oppenheim, E., Zanetti, K.A., Mastri, M.G., and Stover, P.J. 1998. Molecular cloning, characterization and alternative splicing of the human cytoplasmic serine hydroxymethyltransferase gene. Gene 210: $315-324$.

Greenberg, F., Guzzetta, V., Montes de Oca-Luna, R., Magenis, R.E., Smith, A.C.M., Richter, S.F., Kondo, I., Dobyns, W.B., Patel, P.I., and Lupski, J.R. 1991. Molecular analysis of the Smith-Magenis syndrome: A possible contiguous-gene syndrome associated with $\operatorname{del}(17)(\mathrm{p} 11.2)$. Am. J. Hum. Genet. 49: 1207-1218.

Greenberg, F., Lewis, R.A., Potocki, L., Glaze, D., Parke, J., Killian, J., Murphy, M.A., Williamson, D., Brown, F., Dutton, R., et al. 1996. Multi-disciplinary clinical study of Smith-Magenis syndrome (deletion 17p11.2). Am. J. Med. Genet. 62: 247-254.

Hattori, M., Fujiyama, A., Taylor, T.D., Watanabe, H., Yada, T., Park, H-S., Toyoda, A., Ishii, K., Totoki, Y., Choi D-K., et al. The Chromosome 21 Mapping and Sequencing Consortium. 2000. The DNA sequence of human chromosome 21. Nature 405: 311-319.

Helms, J.A., Kim, C.H., Hu, D., Minkoff, R., Thaller, C., and Eichele, G. 1997. Sonic hedgehog participates in craniofacial morphogenesis and is down-regulated by teratogenic doses of retinoic acid. Dev. Biol. 187: 25-35.

Hirotsune, S., Fleck, M.W., Gambello, M.J., Bix, G.J., Chen, A., Clark, G.D., Ledbetter, D.H., McBain, C.J., and Wynshaw-Boris, A 1998. Graded reduction of Pafah1b1 (Lis1) activity results in neuronal migration defects and early embryonic lethality. Nat. Genet. 19: 333-339

Imai, Y., Suzuki, Y., Matsui, T., Tohyama, M., Wanaka, A., and Takagi, T. 1995. Cloning of a retinoic acid-induced gene, GT1, in the embryonal carcinoma cell line P19: Neuron-specific expression in the mouse brain. Mol. Brain Res. 31: 1-9.

Inoue, K., Dewar, K., Katsanis, N., Reiter, L.T., Lander, E.S., Devon, K.L., Wyman, D.W., Lupski, J.R., and Birren, B. 2001. The 1.4-Mb CMT1A duplication/HNPP deletion genomic region reveals unique genome architectural features and provides insights into the recent evolution of new genes. Genome Res. 11: 1018-1033.

Juyal, R.C., Figuera, L.E., Hauge, X., Elsea, S.H., Lupski, J.R., Greenberg, F., Baldini, A., and Patel, P.I. 1996. Molecular analyses of 17p11.2 deletions in 62 Smith-Magenis syndrome patients. Am. J. Hum. Genet. 58: 998-1007.

Kemppainen, R.J. and Behrend, E.N. 1998. Dexamethasone rapidly induces a novel ras superfamily member-related gene in AtT-20 cells. J. Biol. Chem. 273: 3129-3131.

Kleene, K.C., Wang, M-Y., Cutler, M., Hall, C., and Shih, D. 1994. Developmental expression of poly(A) binding protein mRNAs during spermatogenesis in the mouse. Mol. Reprod. Dev. 39: $355-364$

Koop, B.F. 1995. Human and rodent DNA sequence comparisons: A mosaic model of genomic evolution. Trends Genet. 11: 367-371.

Koyama, K., Fukushima, Y., Inazawa, J., Tomotsune, D., Takahashi, N., and Nakamura, Y. 1996. The human homologue of the murine Llglh gene (LLGL) maps within the Smith-Magenis syndrome region in 17p11.2. Cytogenet. Cell Genet. 72: 78-82.

Lander, E.S., Linton, L.M., Birren, B., Nusbaum, C., Zody, M.C., Baldwin, J., Devon, K., Dewar, K., Doyle, M., FitzHugh, W., et al. 2001. Initial sequencing and analysis of the human genome. Nature 409: 860-921.

Li, B. and Trueb, B. 2000. DRG represents a family of two closely related GTP-binding proteins. Biochim. Biophy. Acta. 1491:
196-204.

Li, L., Krantz, I.D., Deng, Y., Genin, A., Banta, A.B., Collins, C.C., Qi, M., Trask, B.J., Kuo, W.L., Cochran, J., et al. 1997. Alagille syndrome is caused by mutations in human Jagged1, which encodes a ligand for Notch1. Nat. Genet. 16: 243-251.

Li, W. and Wang, J.C. 1998. Mammalian DNA topoisomerase III $\alpha$ is essential in early embryogenesis. Proc. Natl. Acad. Sci. 95: 1010-1013.

Liang, Y., Wang, A., Belyantseva, I.A., Anderson, D.W., Probst, F.J., Barber, T.D., Miller, W., Touchman, J.W., Jin, L., Sullivan, S.L., et al. 1999. Characterization of the human and mouse unconventional myosin XV genes responsible for hereditary deafness DFNB3 and shaker 2. Genomics 61: 243-258.

Liburd, N., Ghosh, M., Riazuddin, S., Naz, S., Khan, S., Ahmed, Z., Riazuddin, S., Liang, Y.P., Menon, P.S.N., Smith, T., et al. 2001. Novel mutations of MYO15A associated with profound deafness in consanguineous families and moderately severe hearing loss in a patient with Smith-Magenis syndrome. Hum. Genet. 109: $535-541$.

Liu, X., Szebenyi, D.M.E., Anguera, M.C., Thiel, D.J., and Stover, P.J. 2001. Lack of catalytic activity of a murine mRNA cytoplasmic serine hydroxymethyltransferase splice variant: Evidence against alternative splicing as a regulatory mechanism. Biochemistry 40: 4932-4939.

Lohi, O. and Lehto, V-P. 1998. VHS domain marks a group of proteins involved in endocytosis and vesicular trafficking. FEBS Lett. 440: $255-257$

Lucas, R.E., Vlangos, C.N., Das, P., Patel, P.I., and Elsea, S.H. 2001. Genomic organisation of the $1.5 \mathrm{Mb}$ Smith-Magenis syndrome critical interval: Transcription map, genomic contig, and candidate gene analysis. Euro. J. Hum. Genet. 9: 892-902.

Lupski, J.R. 1998. Genomic disorders: Structural features of the genome can lead to DNA rearrangements and human disease traits. Trends Genet. 14: 417-422.

. 1999. Charcot-Marie-Tooth polyneuropathy: Duplication, gene dosage, and genetic heterogeneity. Pediatr. Res. 45: $159-165$.

Nellen, W. and Lichtenstein, C. 1993. What makes an mRNA anti-sense-itive? Trends Biochem. Sci. 18: 419-423.

Oda, T., Elkahloun, A.G., Pike, B.L., Okajima, K., Krantz, I.D., Genin, A., Piccoli, D.A., Meltzer, P.S., Spinner, N.B., Collins, F.S., et al. 1997. Mutations in the human Jagged1 gene are responsible for Alagille syndrome. Nat. Genet. 16: 235-242.

Ohshiro, T., Yagami, T., Zhang, C., and Matsuzaki, F. 2000. Role of cortical tumour-suppressor proteins in asymmetric division of Drosophila neuroblast. Nature 408: 593-596.

Padmanabhan, R. and Ahmed, I. 1997. Retinoic acid-induced asymmetric craniofacial growth and cleft palate in the TO mouse fetus. Reprod. Toxicol. 11: 843-860.

Palau, F., Lofgren, A., De Jonghe, P., Bort, S., Nelis, E., Sevilla, T., Martin, J.-J., Vilchez, J., Prieto, F., and Van Broeckhoven, C. 1993. Origin of the de novo duplication in Charcot-Marie-Tooth disease type 1A: Unequal nonsister chromatid exchange during spermatogenesis. Hum. Mol. Genet. 2: 2031-2035.

Pandolfi, P.P., Roth, M.E., Karis, A., Leonard, M.W., Dzierzak, E., Grosveld, F.G., Engel, J.D., and Lindenbaum, M.H. 1995. Targeted disruption of the GATA3 gene causes severe abnormalities in the nervous system and in fetal liver haematopoiesis. Nat. Genet. 11: 40-44.

Park, S.-S., Stankiewicz, P., Bi, W., Shaw, C., Lehoczky, J., Dewar, K., Birren, B., and Lupski, J.R. 2002. Structure and evolution of the Smith-Magenis syndrome repeat gene clusters, SMS-REPs. Genome Res. 12: 729-738.

Peng, C.Y., Manning, L., Albertson, R., and Doe, C.Q. 2000. The tumour-suppressor genes $\operatorname{lgl}$ and dlg regulate basal protein targeting in Drosophila neuroblasts. Nature 408: 596-600.

Petrij, F., Giles, R.H., Dauwerse, H.G., Saris, J.J., Hennekam, R.C.M., Masuno, M., Tommerup, N., van Ommen, G-J.B., Goodman, R.H., Peters, D.J.M., et al. 1995. Rubinstein-Taybi syndrome caused by mutations in the transcriptional co-activator CBP. Nature 376: 348-351.

Pilz, D.T., Matsumoto, N., Minnerath, S., Mills, P., Gleeson, J.G., Allen, K.M., Walsh, C.A., Barkovich, A.J., Dobyns, W.B., Ledbetter, D.H., et al. 1998. LIS1 and XLIS (DCX) mutations cause most classical lissencephaly, but different patterns of malformation. Hum. Mol. Genet. 7: 2029-2037.

Potocki, L., Chen, K-S., Park, S-S., Osterholm, D.E., Withers, M.A., Kimonis, V., Summers, A.M., Meschino, W.S., Anyane-Yeboa, K., Kashork, C.D., et al. 2000. Molecular mechanism for duplication 17p11.2: The homologous recombination reciprocal of the 
Bi et al.

Smith-Magenis microdeletion. Nat. Genet. 24: 84-87.

Probst, F.J., Fridell, R.A., Raphael, Y., Saunders, T.L., Wang, A., Liang, Y., Morell, R.J., Touchman, J.W., Lyons, R.H., Noben-Trauth, K., et al. 1998. Correction of deafness in shaker- 2 mice by an unconventional myosin in a BAC transgene. Science 280: $1444-1447$.

Probst, F.J., Chen, K.-S., Zhao, Q., Wang, A., Friedman, T.B., Lupski, J.R., and Camper, S.A. 1999. A physical map of the mouse shaker-2 region contains many of the genes commonly deleted in Smith-Magenis syndrome (del17p11.2p11.2). Genomics 55: 348-352.

Puertollano, R., Randazzo, P.A., Presley, J.F., Hartnell, L.M., and Bonifacino, J.S. 2001. The GGAs promote ARF-dependent recruitment of clathrin to the TGN. Cell 105: 93-102.

Rampazzo, C., Gallinaro, L., Milanesi, E., Frigimelica, E., Reichard, P., and Bianchi, V. 2000. A deoxyribonucleotidase in mitochondria: Involvement in regulation of dNTP pools and possible link to genetic disease. Proc. Natl. Acad. Sci. 97: 8239-8244.

Rothberg, J.M., Jacobs, J.R., Goodman, C.S., and Artavanis-Tsakonas, S. 1990. slit: An extracellular protein necessary for development of midline glia and commissural axon pathways contains both EGF and LRR domains. Genes \& Dev. 4: 2169-2187.

Schmickel, R.D. 1986. Contiguous gene syndromes: A component of recognizable syndromes. J. Pediatr. 109: 231-241.

Schwartz, S., Zhang, Z., Frazer, K.A., Smit, A., Riemer, C., Bouck, J. Gibbs, R., Hardison, R., and Miller, W. 2000. PipMaker: A web server for aligning two genomic DNA sequences. Genome Res. 10: $577-586$

Seki, T., Seki, M., Katada, T., and Enomoto, T. 1998. Isolation of a cDNA encoding mouse DNA topoisomerase III which is highly expressed at the mRNA level in the testis. Biochim. Biophys. Acta 1396: $127-131$.

Seranski, P., Heiss, N.S., Dhorne-Pollet, S., Radelof, U., Korn, B., Hennig, S., Backes, E., Schmidt, S., Wiemann, S., Schwarz, C.E., et al. 1999. Transcription mapping in a medulloblastoma breakpoint interval and Smith-Magenis syndrome candidate region: Identification of 53 transcriptional units and new candidate genes. Genomics 56: 1-11.

Seranski, P., Hoff, C., Radelof, U., Hennig, S., Reinhardt, R., Schwartz, C.E. Heiss, N.S., and Poustka, A. 2001. RAI1 is a novel polyglutamine encoding gene that is deleted in Smith-Magenis syndrome patients. Gene 270: 69-76.

Shaffer, L.G., Ledbetter, D.H., and Lupski, J.R. 2001. Molecular cytogenetics of contiguous gene syndromes: Mechanisms and consequences of gene dosage imbalance. In The metabolic and molecular bases of inherited disease, 8th ed. (eds. C.R. Scriver et al.), pp. 1291-1324. McGraw-Hill, New York.

Sheng, M. and Sala, C. 2001. PDZ domains and the organization of supramolecular complexes. Ann. Rev. Neurosci. 24: 1-29.

Shields, D.J., Agellon, L.B., and Vance, D.E. 2001. Structure, expression profile and alternative processing of the human phosphatidylethanolamine N-methyltransferase (PEMT) gene. Biochim. Biophys. Acta 1532: 105-114.

Shimano, H., Shimomura, I., Hammer, R.E., Herz, J., Goldstein, J.L, Brown, M.S., and Horton, J.D. 1997. Elevated levels of SREBP-2 and cholesterol synthesis in livers of mice homozygous for a targeted disruption of the SREBP-1 gene. J. Clin. Invest. 100: 2115-2124.

Smith, A.C.M., McGavran, L., Robinson, J., Waldstein, G., Macfarlane, J., Zonona, J., Reiss, J., Lahr, M., Allen, L., and Magenis, E. 1986. Interstitial deletion of (17)(p11.2p11.2) in nine patients. Am. J. Med. Genet. 24: 393-414.

Stankiewicz, P. and Lupski, J.R. 2002. Genome architecture, rearrangements, and genomic disorders. Trends Genet. 18: 74-82.

Stratton, R.F., Dobyns, W.B., Greenberg, F., DeSana, J.B., Moore, C., Fidone, G., Runge, G.H., Feldman, P., Sekhon, G.S., Pauli, R.M., et al. 1986. Interstitial deletion of (17)(p11.2p11.2): Report of six additional patients with a new chromosome deletion syndrome. Am. J. Med. Genet. 24: 421-432.

Tomotsune, D., Shoji, H., Wakamatsu, Y., Kondoh, H., and Takahashi, N. 1993. A mouse homologue of the Drosophila tumour-suppressor gene $l(2) g l$ controlled by Hox-C8 in vivo. Nature 365: 69-72.

$\mathrm{Tu}, \mathrm{Y}$. and $\mathrm{Wu}, \mathrm{C} .1999$. Cloning, expression and characterization of a novel human Ras-related protein that is regulated by glucocorticoid hormone. Biochim. Biophys. Acta 1489: 452-456.

Van Esch, H. and Devriendt, K. 2001. Transcription factor GATA3 and the human HDR syndrome. Cell Mol. Life Sci. 58: 1296-1300.

Venter, J.C., Adams, M.D., Myers, E.W., Li, P.W., Mural, R.J., Sutton, G.G., Smith, H.O., Yandell, M., Evans, C.A., Holt, R.A., et al. 2001. The sequence of the human genome. Science 291: $1304-1351$.

Walkey, C.J., Cui, Z., Agellon, L.B., and Vance, D.E. 1996. Characterization of the murine phosphatidylethanolamine $\mathrm{N}$-methyltransferase-2 gene. J. Lipid Res. 37: 2341-2350.

Wang, A., Liang, Y., Fridell, R.A., Probst, F.J., Wilcox, E.R., Touchman, J.W., Morton, C.C., Morell, R.J., Noben-Trauth, K., Camper, S.A., et al. 1998. Association of unconventional myosin MYO15 mutations with human nonsyndromic deafness DFNB3. Science 280: 1447-1451.

Wang, Z.-G., White, P.S., and Ackerman, S.H. 2001. Atp11p and Atp $12 p$ are assembly factors for the $F_{1}$-ATPase in human mitochondria. J. Biol. Chem. 276: 30773-30778.

Yokoyama, C., Wang, X., Briggs, M.R., Admon, A., Wu, J., Hua, X., Goldstein, J.L., and Brown, M.S. 1993. SREBP-1, a basic-helix-loop-helix-leucine zipper protein that controls transcription of the low density lipoprotein receptor gene. Cell 75: $187-197$

\section{WEB SITE REFERENCES}

http://bio.cse.psu.edu/pipmaker/; PipMaker to compare two or more noncontinuous DNA sequences.

http://ftp.genome.washington.edu/cgi-bin/RepeatMasker; RepeatMasker to detect and mask human and mouse interspersed repeat sequences.

http://genomic.sanger.ac.uk/gf/gfb.html; FGENES for gene prediction.

http://pfam.wustl.edu; Pfam 6.6 to analyze proteins.

http://www.celera.com; Celera private database.

http://www.ch.embnet.org/software/TMPRED_form.html; TMpred for transmembrane regions.

http://www.ebi.ac.uk/interpro; InterPRO for domains.

http://www-genome.wi.mit.edu/genome_software/other/primer1.html; Primer 3 to design primers.

http://www.hgmp.mrc.ac.uk/Registered/Webapp/nix; NIX for DNA sequence analysis.

http://www.ncbi.nlm.nih.gov; NCBI public database.

http://www.tigr.org; BAC ends database.

Received December 27, 2001; accepted in revised form March 19, 2002. 


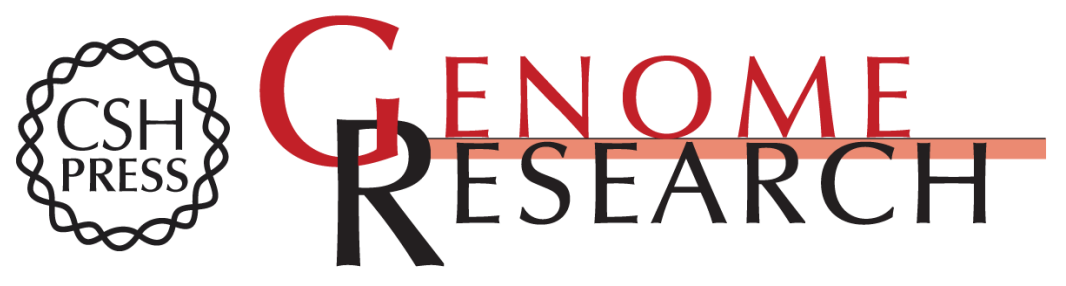

\section{Genes in a Refined Smith-Magenis Syndrome Critical Deletion Interval on Chromosome 17p11.2 and the Syntenic Region of the Mouse}

Weimin Bi, Jiong Yan, Pawel Stankiewicz, et al.

Genome Res. 2002 12: 713-728

Access the most recent version at doi:10.1101/gr.73702

References This article cites 75 articles, 16 of which can be accessed free at: http://genome.cshlp.org/content/12/5/713.full.html\#ref-list-1

\section{License}

Email Alerting

Receive free email alerts when new articles cite this article - sign up in the box at the Service top right corner of the article or click here.

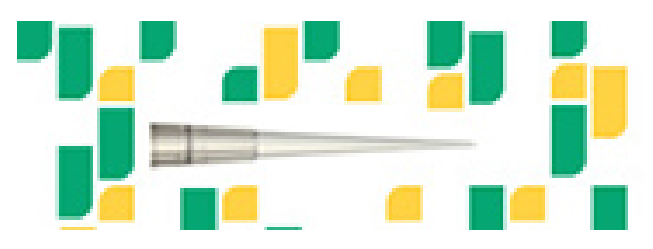

To subscribe to Genome Research go to: https://genome.cshlp.org/subscriptions 